\title{
Dietary phosphatidylcholine promotes breast cancer in the hyperlipidemic E0771 murine model
}

Fredrick 0 Onono ( $\square$ foon222@uky.edu )

University of Kentucky College of Medicine https://orcid.org/0000-0003-3827-5045

\section{Lakshman Chelvarajan \\ University of Kentucky \\ Baoxiang Yan \\ University of Kentucky \\ Ebubechi Adindu \\ University of Kentucky \\ Esias Bedingar \\ Harvard University}

\section{Research}

Keywords: Breast cancer, Phosphatidylcholine, Casein, Autotaxin, lysophosphatidic acid, mass spectrometry

Posted Date: April 29th, 2020

DOI: https://doi.org/10.21203/rs.3.rs-25261/v1

License: (c) (i) This work is licensed under a Creative Commons Attribution 4.0 International License.

Read Full License 
3 Esias Bedingar ${ }^{1, *}$, Baoxiang Yan ${ }^{1,2}$, Ebubechi Adindu ${ }^{1}$, Lakshman Chelvarajan ${ }^{1}$ and Fredrick O. Onono ${ }^{1,2}$, 4

$5 \quad{ }^{1}$ Division of Cardiovascular Medicine and The Gill Heart and Vascular Institute,

$6 \quad{ }^{2}$ Markey Cancer Center,

7 University of Kentucky Colleges of Medicine, Lexington, KY 40536-0200

8 *Current address; Harvard T.H. Chan School of Public Health, Harvard University, 677 Huntington Ave, 9 Boston, MA 02115

11 Running title: Phosphatidylcholine-rich dietary casein promotes breast cancer

\section{Key words}

14 Breast cancer; Phosphatidylcholine, Casein, Autotaxin, lysophosphatidic acid, mass spectrometry

Corresponding author: Fredrick O. Onono, PhD

741 S. Limestone, BBSRB Room B353

University of Kentucky

Lexington, KY 40536

Phone: 859-323-3243; Fax: 859-257-3235

Email: foon222@uky.edu

23 Conflict of interest statement: The authors declare no potential conflicts of interest. 


\section{Non standard abbreviations}

25 PC: Phosphatidylcholine; ATX: Autotaxin; ENPP: ectonucleotide pyrophosphatase/phosphodiesterase; LDLR:

26 low-density lipoprotein receptor; LPA: Lysophosphatidic Acid; LPC: lysophosphatidylcholine; LysoPLD:

27 Lysophospholipase D; PAT-505: [3-((6-chloro-2-cyclopropyl-1-(1-ethyl-1H-pyrazol-4-yl)-7-fluoro-1H-indol-3-

28 yl) thio)-2-fluorobenzoic acid sodium salt]; PF8380: 4-[3-(2,3-dihydro-2-oxo-6-benzoxazolyl)-3-oxopropyl]-

29 (3,5-dichlorophenyl)methyl ester-1-piperazinecarboxylic acid; VFT: "Vitamin-Free" Test; WD: Western Diet; 30 HFD: High Fat Diet 


\section{Background}

33 Cancer cells are characterized by aberrant phosphatidylcholine (PC) metabolism. PC can be synthesized de novo or absorbed from diet, after digestion, by the intestinal enterocytes. Here, we investigated the association of dietary intake of PC and breast cancer development in mice.

\section{Methods}

We used tandem mass spectrometry methods to quantitate PC content of various fat sources used to manufacture rodent diets. Rodent diets were then formulated with either casein or amino acids in place of casein. To test the effects of dietary PC on tumor growth we fed low density lipoprotein receptor-null (LDLR/-) mice high fat diets formulated with casein (high PC) or amino acids in place of casein (low PC).

Endogenous PC biosynthesis and levels of total circulated plasma PC was monitored using stable isotope tracer choline and mass spectrometry analysis. Tumors were induced in mice after 12 weeks of high fat diet feeding. Since PC-derived molecules are important transducers of mitogenic signals, we tested the effects of inhibiting production of lysophosphatidic acid (LPA) using a recently described autotaxin (ATX) inhibitor. Finally, plasma inflammatory cytokine levels were analyzed to determine the effects of diets and ATX inhibition on systemic cytokine milieu.

\section{Results}

We found that casein is the main source of PC when present in rodent diets. Replacing casein with amino acids increased the relative proportion of endogenously biosynthesized PC in mouse plasma. Compared to diets containing casein, amino acid-defined diets decreased primary tumor growth in the hyperlipidemic estrogenreceptor positive E0771 breast cancer mouse model. Inhibition of autotaxin with the potent inhibitor PAT-505 did not attenuate breast cancer development in these hyperlipidemic mice. Further, replacing casein with amino acids or treatment with PAT-505 significantly reduced systemic markers of inflammation.

\section{Conclusion}

Our results show that casein is a significant source of PC when present in rodent diets. Diets formulated with amino acids in place of casein have higher proportion of circulating PC from the endogenous biosynthetic pool. Casein-containing high fat diets promote primary breast tumor development in mice through mechanisms that involve systemic inflammation but is independent of LPA production by autotaxin. 


\section{Introduction}

Breast cancer is the most common cancer in women worldwide and the second highest cause of cancer mortality for women in the United States[1]. Abnormal phosphatidylcholine (PC) metabolism is emerging as one of the most consistent metabolic hallmarks that is associated with oncogenesis and tumor progression in multiple cancers including breast cancer[2]. Detection of total PC and PC metabolite levels have been proposed as putative diagnostic biomarkers for monitoring tumor progression and response to therapy. Although most of the PC can be synthesized de novo from free choline using cytidine diphospho-choline (Kennedy) pathway and by sequential methylation of phosphatidylethanolamine, humans require additional PC from dietary sources[3, 4]. As the predominant phospholipid of biological membranes $\mathrm{PC}$ is the most abundant phospholipid in a wide range of foods[5]. Adult human dietary intake of PC is approximately 6 to $10 \mathrm{~g} / \mathrm{day}[6]$. In addition, PC is also the major phospholipid of mammalian bile which can be secreted as much as $6 \mathrm{~g} /$ day during digestion to emulsify dietary triglycerides[7, 8]. Moreover, a PC enriched fraction produced through commercial purification, lecithin, is often added to food as an emulsifying agent or consumed as a nutritional supplement. Both dietary and bile derived PC can be absorbed as intact PC but the main mechanism of uptake involves hydrolysis by phospholipase A2 (PLA2) to generate LysoPC (LPC) and a free fatty acid both of which are actively assimilated by enterocytes[9].

PC is a significant source of the lipid mediator lysophosphatidic acid (LPA), a family of bioactive lysophospholipids that act as signaling molecules primarily through actions at cell-surface G-protein coupled receptors to promote cellular proliferation, migration, and survival[10]. There are two major pathways for LPA production from PC [11]. However, majority of the circulating LPA is produced by autotaxin (ATX), a secreted phospholipase D[12]. Encoded by the ecto-nucleotide pyrophosphatase/phosphodiesterase 2 (ENPP2) gene, ATX hydrolyzes primarily LPC to LPA[13]. ATX was originally identified as an autocrine motility-promoting factor that causes mitosis and angiogenesis in cancer cells[14]. Many normal cells and several chronic inflammatory diseases and different types of cancer express ATX. Most biologic fluids and plasma also contain ATX. In mouse, embryonic development ATX expression is necessary, as ubiquitous genetic deletion of ATX is lethal. However, in adult mice, ubiquitous genetic deletion and pharmacological inhibition of ATX are well tolerated[15]. The importance of ATX has been demonstrated in many breast cancer studies[16-23]. Transgenic overexpression of ATX, and LPA receptors ( $\mathrm{LPA}_{1}, \mathrm{LPA}_{2}$, or $\left.\mathrm{LPA}_{3}\right)$ in mammary cells enhance spontaneous metastatic mammary tumors in mice[20]. ATX/LPA promote the migration of breast cancer cells in vitro and ATX is among the most upregulated genes in metastatic cancers. ATX has therefore emerged as a promising therapeutic target giving rise to the development of a large number of ATX inhibitors[16, 24, 25]. Inhibition of ATX was demonstrated for the first time to decrease breast tumor growth and metastasis in the syngeneic 4T1 orthotopic mouse model using the ATX inhibitor, ONO-8430506[26]. 
Animal models are invaluable resources for cancer research and drug efficacy testing. However, many

94 studies using animal models draw conclusions about dietary effects from comparisons of different diets without making considerations for PC composition in the diets. Typically, the PC content of laboratory animal diets is not reported in the literature or provided by the manufacturers. Therefore, we examined the PC composition of different fat sources in rodent diets and the effects of manipulating dietary PC levels on breast cancer development. This was extended to studies in which ATX inhibition was combined with dietary PC depletion. We used the hyperlipidemic C57BL/6 LDL receptor-null (LDLR-/-) mice since these mice are reported to exhibit an accumulation of ATX-derived LPA when fed diets containing high fat contents[27, 28]. Our studies show that milk casein is the main source of PC when present in rodent diets. Stripping of casein and other sources of fat with denatured alcohol reduces PC levels contained in these constituents by up to $70 \%$. Furthermore, replacing casein in diets with amino acids decreases PC contents by nearly $90 \%$. The results of our study show that casein in rodent diets promotes greater tumor development compared to diets in which casein is replaced with amino acids. However, inhibition of ATX was without effect on primary tumor growth in PC-rich diet fed mice and reversed the beneficial effects of PC depletion on primary tumor growth. Feeding mice amino acid-defined diets or inhibiting ATX significantly reduced plasma inflammatory cytokine levels. Our findings suggest that the beneficial effects of replacing milk casein with amino acids is through a mechanism that is independent of the ATX-derived LPA signaling. 
Reagents

Unless otherwise indicated, reagents were from Millipore-Sigma. Recombinant mouse ATX was from R\&D Systems (Minneapolis, MN). Recombinant human ATX was from Echelon (Salt Lake City, UT). Lipids and lipid standards were sourced from Avanti Polar Lipids (Alabaster, AL).

\section{E0771 cell culture}

E0771 murine breast cancer line originally isolated as a spontaneous tumor from C57BL/6 was purchased from CH3 BioSystems (Buffalo, NY). The cells were maintained in RPMI 1640 medium supplemented with 10 $\mathrm{mmol} / \mathrm{L}$ HEPES, 10\% Fetal Bovine Serum, penicillin (100 units $/ \mathrm{ml})$ and streptomycin $(100 \mu \mathrm{g} / \mathrm{ml})$ cultured at $37^{\circ} \mathrm{C}$ in a humidified atmosphere of $5 \% \mathrm{CO}_{2}$ in air. Cells in cultures were washed with PBS, trypsinized and resuspended in Hank's balanced salt solution (HBSS) at 5,000,000 cells/ml.

\section{Rodent diet formulations}

To test the hypothesis that casein-containing diets could promote tumor development in hyperlipidemic mice, we formulated western and high fat diets in collaboration with Envigo diet manufacturers (Madison, WI). Western diets (42\% Kcal from fat) were modeled around the diet TD.88137[29] while high fat diets (60\% kcal from fat) were modeled on TD.06414[30]. Casein diets were formulated with casein or "Vitamin-free" Test (VFT) Casein (Envigo, Madison, WI). The amino acid defined diets (isonitrogenous diets) were manufactured using the amino acid profile of casein as formulated for diet TD.140088 with modifications equivalent to casein-containing diets. Aspartic acid (Asp) and glutamine (Gln) are non-essential amino acids and not included in the amino acid (AA) profile of casein. These amino acids were added to the diets at similar levels found in other AA-defined diets (such as TD.99366). Asp was added at approximately half of the level of Asp in other AA defined diets. Gln was added at a similar rate as Glu. Cysteine was added to the casein diet to balance the amino acid profile - casein is limiting in sulfur AA. Since casein is a significant source of calcium and phosphorus the levels of these minerals were also adjusted in the diets. VFT casein reduces fat and moisture in the casein product and increases the concentration of protein. Therefore, we adjusted the inclusion rate of VFT casein to better match the total protein levels. For all diets $50 \mathrm{~g} / \mathrm{kg}$ maltodextrin was added to improve pelleting of the amino acid and VFT-casein diets. Diets were color coded by adding food colors for ease of identification. Detailed nutritional composition of the formulated diets can be found in Supplementary Tables 12. 
$\mathrm{PC}$ in systemic circulation can be derived from diet or from de novo synthesis using choline as substrate. To interrogate the contribution of casein in rodent diets to plasma PC pool, high fat diets formulated with casein or amino acids were designed to contain deuterium labeled choline as the sole source of dietary free choline in the diets. The deuterium label in choline served as stable isotope tracer to track endogenous PC biosynthesis. Fiveweek-old female LDL receptor deficient $\left(\mathrm{LDLr}^{-/}\right) \mathrm{C} 57 \mathrm{BL} / 6$ mice were purchased from Jackson laboratory (Bar Harbor, Maine) and maintained on 12-hour light/dark cycle at the University of Kentucky Animal Care Facility. The mice were fed water and standard rodent chow diet (2014 Teklad Harlan Rodent Diet) ad libitum for 1 week to acclimatize to the laboratory conditions before being assigned randomly into groups to receive the diets containing either labeled or unlabeled choline. After 8 weeks of ad libitum feeding, blood was drawn from mice, plasma prepared and frozen at $-80^{\circ} \mathrm{C}$ for further lipid analysis as described below.

\section{Animals and syngeneic orthotopic mouse model of breast cancer.}

Animal experiments were approved by the Institutional Animal Care and Use Committee of the University of Kentucky. Five-week-old female LDLr ${ }^{-/}$C57BL/6 mice were purchased from Jackson laboratory (Bar Harbor, Maine) and maintained on 12-hour light/dark cycle at the University of Kentucky Animal Care Facility. The mice were fed water and standard rodent chow diet (2014 Teklad Harlan Rodent Diet) ad libitum for 1 week to acclimatize to the laboratory conditions before being assigned randomly into groups to receive the assigned diets. Food consumption was monitored by weighing food pellets before and after replacement. Blood was drawn via submandibular bleeding into Ethylenediaminetetraacetic acid (EDTA) coated tubes (BD Microtainer) at the onset of high fat feeding and biweekly thereafter. Plasma was prepared immediately and stored frozen at $80^{\circ} \mathrm{C}$ until processing for measurements of lipids (PC, LPC and LPA), ATX inhibitors and other markers as needed. Twelve weeks after initiating feeding, mice were anesthetized, a small incision made and syngeneic estrogen receptor positive (ER+) E0771 tumor cells (500,000 cells suspended in $100 \mu 1 \mathrm{HBSS})$ were injected into the inguinal mammary fat pad using an insulin syringe. The incision was then closed with a wound clip. When tumors became palpable after 4-5 days, two orthogonal caliper measurements were taken and tumor volumes estimated using the formula width ${ }^{2} \times$ length/2. Primary tumors were allowed to grow until they reached the maximum allowable size of $1 \mathrm{~cm}^{3}$. The primary tumors were resected and animals kept for a further 2 weeks for spontaneous metastasis when the animals were euthanized and various organs harvested. To analyze lung metastatic burden, dissected lungs were stained with India ink to visualize metastatic nodules and the number of visible surface nodules counted. 
PAT-505 [3-((6-chloro-2-cyclopropyl-1-(1-ethyl-1H-pyrazol-4-yl)-7-fluoro-1H-indol-3-yl) thio)-2fluorobenzoic acid sodium salt was obtained from PharmAkea (San Diego, CA) under a material transfer agreement. For oral dosing of PAT-505 at $30-\mathrm{mg} / \mathrm{kg}$ body weight a $7.5 \mathrm{mg} / \mathrm{mL}$ solution was prepared by adding room temperature $0.5 \%$ methyl cellulose to PAT-505 in a scintillation vial and heating to $\sim 60-70^{\circ} \mathrm{C}$ to dissolve. The solution was sonicated for 3-5 minutes until it became clear. The dosing solution was stored at room temperature for daily dosing for up to 1 week before a new solution could be prepared. One day prior to E0771 cell inoculation, treatment of animals with PAT-505 or $0.5 \%$ methyl cellulose (MC Vehicle) by oral gavage was initiated and continued twice daily until the animals were sacrificed.

\section{Measurement of bioactive lipids and PAT-505 by mass spectrometry}

PC and LPA measurements were performed using established methods previously described[31-38]. PC species and PAT-505 were measured using high performance liquid chromatography (HPLC) electrospray ionization (ESI) tandem mass spectrometry (MS) using AB Sciex 4000 Q-Trap linear ion trap triple quadrupole and AB Sciex 5600 Quadrupole time of flight mass spectrometers (Sciex, Framingham, MA). Deuterated lipids were initially analyzed using Fourier Transform Mass Spectrometry (FTMS) and validated using the Thermo QExactive. The samples were injected by direct infusion into the UHRMS (THERMO Orbitrap Fusion ${ }^{\mathrm{TM}}$ Tribrid $^{\mathrm{TM}}$, resolving power of 500,000 at m/z 200) via nanoESI (Advion TriVersa NanoMate ${ }^{\circledR}$ ) in positive mode. Ten microscans were added to produce a single MS1 full scan (m/z 150-1600) with total acquisition time of 10 minutes. Lock mass (EASY-IC ${ }^{\mathrm{TM}}$ ) was used for improved reproducibility throughout the scans. Scans in each acquired spectrum were averaged using Xcalibur 4.1(THERMO Scientific ${ }^{\mathrm{TM}}$ ). LPA species were measured using the AB Sciex Triple Quad 6500 (Sciex, Framingham, MA). PC in the various rodent diets were extracted using modified Bligh and Dyer Method. Briefly, milligram amounts of diets were respectively weighed from randomly selected diet pellets and extracted in a solvent system consisting of chloroform/methanol/water 2:2:18 (v/v/v) after intermittent sonication in $8 \mathrm{ml}$ glass tubes. To monitor analyte recovery, 17:0 LPC (Avanti Polar Lipids, Alabaster, AL) was included in each tube. Plasma PC and LPA were extracted from $50 \mu \mathrm{l}$ of plasma using acidified organic solvents with the inclusion of $10 \mu 1$ of Avanti Splash ${ }^{\circledR}$ Lipidomix ${ }^{\circledR}$ Mass spec Standard (for PC) and 17:0 LPA for LPA species (Avanti Polar Lipids, Alabaster, AL) as internal or recovery standards. Quantitation of lipids was done by selected ion monitoring mode HPLC MS/MS using calibration curves generated using independently quantitated standards. Data for rodent diet PC were quantified based on the recovery of 17:0 LPC and normalized to the weights of the diets respectively. Data for PC in diets or dietary constituents were normalized to their respective diet or constituent mass while data for plasma PC and LPA were normalized to the lipid standards contained in the deuterated Avanti Splash $\mathbb{R}$ 
Lipidomix ${ }^{\circledR}$ standard mixture and 17:0 LPA. PAT-505 was extracted using a previously described method with the inclusion of PF8380 as recovery standard and analyzed using the AB Sciex 4000 Q-Trap linear ion trap triple quadrupole mass spectrometer[39]. Quantitation of PAT-505 was done using calibration curves from standards run independently.

\section{Measurement of ATX activity}

To validate the potency of PAT-505 in vitro, we analyzed the activities of recombinant mouse and human ATX against a panel of lysophosphatidylcholine (LPC) in the presence or absence of PAT-505. ATX catalyzes the hydrolysis of LPC to LPA and choline. The released choline is oxidized by choline oxidase to betaine and hydrogen peroxide which is detected in a color reaction commonly known as TOOS (N-ethyl-N-(2-hydroxy-3sulfopropyl)-3-methylaniline) assay[40]. We used LPC species with saturated fatty acyl chains 16:0 LPC and 18:0 LPC, unsaturated fatty acyl chain 18:1 LPC and the synthetic unnatural 17:0 LPC. The ATX/LysoPLD activity reaction containing ATX and LPC was performed in $100 \mu \mathrm{lbuffer}(50 \mathrm{mM}$ Tris-HCl pH 8.0, $5 \mathrm{mM}$ $\mathrm{MgCl}_{2}, 5 \mathrm{mM} \mathrm{CaCl}, 140 \mathrm{mM} \mathrm{NaCl}, 1 \mathrm{mg} / \mathrm{ml}$ Fatty acid free BSA, and $0.01 \%$ Brij-35 (w/v) for 2 hours at $37^{\circ} \mathrm{C}$ with intermittent shaking. To test the inhibitory effects of PAT-505, we pre-incubated PAT-505 with recombinant ATX for 30 minutes before adding the respective LPC substrates. The choline released was detected by adding $100 \mu \mathrm{l}$ of detection/color reagent consisting of $50 \mathrm{mM}$ Tris-HCL pH 8, $4.5 \mathrm{mM} \mathrm{MgCl} 24.5$ $\mathrm{mM}$ 4-aminoantipyrine, $2.7 \mathrm{mM}$ TOOS, 20 units $\mathrm{ml}^{-1}$ horseradish peroxide and 3 units $\mathrm{ml}^{-1}$ choline oxidase and incubating for 15 minutes before measuring the absorbance at $555 \mathrm{~nm}$. Absorbance values were plotted against the log concentration of PAT-505.

\section{Quantitation of plasma cytokines and chemokines by Multiplex assay}

Plasma samples from tumor-induced PAT-505 and vehicle control-treated mice were analyzed for the levels of circulating cytokines and chemokines. Measurements were performed using the Milliplex Mouse Cytokine/Chemokine Premixed 32-Plex and TGF-beta 1, 2, 3 magnetic bead Kits (Millipore Corp, Billerica, MA) according to the manufacturer's protocol. Processed plates were measured on the Luminex Xmap MAGPIX system (Luminex Corp, Austin, TX), as per the manufacturer's instructions. The following cytokines/chemokines were measured: G-CSF, Eotaxin, GM-CSF, IFN-g, IL-1a, IL-1b, IL-2, IL-3, IL-4, IL-5, IL-6, IL-7, IL-9, IL-10, IL-12 p40, IL-12 p70, IL-13, IL-15, IL-17，LIF, LIX, IP-10, KC, MCP-1, MIP-1a, MIP-1b, M-CSF, MIP-2, MIG, RANTES, VEGF, TNF-a, TGF- $\beta$ 1, TGF- $\beta 2$ and TGF- $\beta$ 3. The values below standard curve were denoted as zero for statistical analyses while the data were reported as means \pm standard errors of the means (SEM). 
235 Results were expressed as mean \pm standard error of the means (SEM). Statistical analyses were performed 236 using the Prism 7 package (GraphPad, La Jolla, CA) and SigmaStat (San Jose, CA, USA). Unpaired two-

237 tailed Student's $t$-test or analysis of variance (one way or multiple comparisons) was performed for 238 comparisons between the groups. Comparisons in tumor growth kinetics between groups were performed 239 using 2-way ANOVA with post hoc Bonferroni-corrected t test. Values of $p<0.05$ were considered 240 statistically significant. 


\section{Results}

\section{Casein is the major source of Phosphatidylcholine when added as a constituent of rodent diets}

We obtained the ingredients commonly used as fat sources to formulate rodent diets from Envigo (Madison, WI) and quantitated PC in the separate components. As shown in Table 1, PC was detected in all of the preparations tested. Lard and anhydrous milk, which are common fat sources in high fat diets, are rich in PC. Other components used in rodent diets to substitute for lard and anhydrous milk also contain detectable PC amounts. The most striking observation however is that PC is highly abundant in casein. Casein is usually added to diets as a protein source. In our analysis, the quantities of PC in casein were approximately 100-fold higher compared to traditional fat sources. We also observed that PC levels can be significantly reduced in the respective sources by stripping with organic solvents. Levels of PC were reduced in "Vitamin-Free" Test (VFT) Casein by about $70 \%$. VFT-casein is produced by extracting casein obtained from lactic acid precipitation of skim milk with hot denatured ethanol. Compared to regular casein, VFT-casein is reported by the manufacturer to contain less fat, less moisture and more protein. As with hot denatured ethanol, we also observed that tochopherol stripping of lard and corn oil reduced PC levels in these constituents substantially by up to 50-75\% (Table. 1). Analysis of the individual PC species present in these dietary components reveal the presence of PCs of different carbon lengths and fatty acyl chain saturations, with PC (34:1) being the most abundant (Table 2).

Having established that casein is the major source of PC we formulated different types of rodent diets based on the composition of the widely used western diet TD.88137 (42\% Kcal from fat) and high fat diet TD.06414 (60\% Kcal from fat), respectively. The casein content in the western diet and high fat diet were kept at $195 \mathrm{~g} / \mathrm{kg}$ and $295 \mathrm{~g} / \mathrm{kg}$, respectively. Western diets were formulated with $210 \mathrm{~g} / \mathrm{kg}$ anhydrous milkfat while high fat diets contained $310 \mathrm{~g} / \mathrm{kg}$ lard. Three different types of western diet were designed based on the amino acid composition of casein. One of the diets contained casein (Casein Diet). The second diet was made with VTF-Casein while the third diet was constituted by replacing casein with amino acids (AA diets) based on the amino acid profile of casein as provided Envigo. Amino acid composition was adjusted to be equivalent to the levels found in casein. Care was taken to also match the levels of calcium, phosphorus and sucrose in both diets. High fat diets on the other hand were formulated with either casein or amino acids. To determine whether the expected alteration of PC levels occurred in the different formulated diets, lipids were extracted from these diets and their PC compositions analyzed by LC/MS/MS. The results of our analysis show that both the western and high fat diets containing casein had the highest PC contents, while diets formulated with VFT Casein or amino acids had significantly reduced levels of PC (Fig 1). Whereas casein is used primarily as a source of protein in standard laboratory rodent diets from multiple manufacturers these observations identify casein as also the major contributor of dietary PC in these diets. 


\section{Dietary casein contributes to circulating plasma PC.}

To monitor the contribution of dietary casein to systemic PC pool, we formulated high diets with casein or amino acids based on the amino acid profile of casein and assessed incorporation of dietary choline into plasma PC using Fourier Transform Mass Spectrometry. (FTMS). Fig. 2A depicts a representative section of the spectrum of the MS Scan and labeling of PC(34:2), one of the most abundant PC in the plasma of a mouse fed amino acid defined diet containing deuterium labeled choline. From their calculated exact masses, the highlighted peaks in the spectrum are the signals for D0-PC(34:2) at $\mathrm{m} / \mathrm{z} 758.56927$ formed from unlabeled choline, and D9-PC(34:2) at $\mathrm{m} / z$ 767.62579 which would have been generated from the deuterated choline supplied in the diets. We further analyzed these samples by LC/MS/MS using the Thermo Q-Exactive All-ions fragmentation (AIF) in positive mode to generate the product ions. As shown in Fig. $2 \mathrm{~B}$ and $\mathrm{C}$, we observed a pattern corresponding to the D0- and D9-choline present in the PC(34:2), represented by the $m / z 184$ and $m / z$ 193 masses of the choline ion moieties respectively. These observations validated biosynthesis of PC from exogenously provided choline and confirm that tracer choline is utilized at high levels and at various intensities. To establish the relative quantities of individual PC species in plasma, we used the high resolution AB Sciex 5600 Quadrupole time of flight (TOF) mass spectrometer. TOF MS data were acquired in positive mode, ions corresponding to the e $\mathrm{m} / \mathrm{z}$ ratios of individual PCs extracted and analyzed using the AB Sciex OS Analytics program. A comparison of the ratios of deuterated PC to the unlabeled PC of the most abundant PCs showed that there was a higher degree of labeled PC in plasma from mice that were fed with the amino acid-defined diets Fig. 2D-I.

\section{Casein promotes breast cancer in E0771 hyperlipidemic mice fed high fat diet.}

To understand the effects of dietary casein and inhibition of autotaxin on breast cancer development in hyperlipidemic mice, we fed age-matched LDLR-/- mice with high fat diets $(60 \% \mathrm{kcal}$ from fat) formulated with casein or defined amino acids in place of casein (AA diets). After 12 weeks of feeding, breast cancer was induced in these mice by injection of the syngeneic E0771 mammary tumor cells into the inguinal mammary fat pads while treating with either $30 \mathrm{mg} / \mathrm{kg}$ ATX inhibitor PAT-505 or methyl cellulose vehicle control twice daily. In the liver fibrosis mouse models, PAT-505 was efficacious and shown to inhibit ATX activity in plasma and liver tissues after oral administration[39]. We observed reduced primary tumor growth in mice that were fed amino acid defined diets compared to casein-containing diet (Fig. 3A). There was no significant difference in primary tumor volumes and excised tumor masses between PAT-505-and vehicle-treated mice when the animals were fed with casein-containing diet. However, treatment with PAT-505 abolished the tumor growth reducing effects of amino acid-defined diet since tumor volume (Fig. 3A) and excised tumor masses 
(Fig. 3B) were higher in PAT-505 treated mice compared to the vehicle-treated mice. Previous studies using a potent ATX inhibitor ONO-8430506 and the highly metastatic 4T1 breast cancer models reported that long term treatment with the ATX inhibitor did not result in significant difference in primary tumor size[26]. The authors observed an initial reduction of tumor growth in ONO-8430506-treated mice which eventually caught up to the vehicle group resulting in comparable primary tumor development. In our studies, treatment with PAT-505 increased the number of metastatic nodules in the lungs of mice that received casein-containing diet but did not have significant metastatic effects in mice that were fed amino acid-defined diet (Fig. 3C).

\section{In vivo Bioavailability of PAT-505 in breast cancer mouse model of cancer and in vitro drug potency.}

Because of the results in Fig. 3 showing a lack of breast tumor growth inhibition by PAT-505, we decided to develop methods to determine the bioavailability of PAT-505 in harvested plasma and tissues and also validate the drug's potency in vitro. The concentration of PAT-505 was assessed in plasma obtained from mice ( $\mathrm{n}=7$ 9/group) implanted with tumor and receiving twice daily oral administration of the drug. Using tandem MS methods we confirmed the bioavailability of PAT-505 in plasma and tissues harvested from our mice (Fig. 4A). We observed very high levels of circulating PAT-505 in plasma, reaching concentration levels of $60 \mu \mathrm{M}$ after one week of drug administration (Fig. 4B). These levels are consistent with the reported pharmacokinetic (PK) of PAT-505 as assessed in mice and rats[39]. We also determined PAT-505 levels in tissues that were harvested after the animals were sacrificed. PAT-505 was detected in the all the organs analyzed with the highest levels detected in the intestines and liver, while the lowest levels were present in the brain and spleen (Fig. 4C). PAT505 is reported to have nanomolar potency (in vitro $\mathrm{IC}_{90}$ of $\sim 630 \mathrm{nM}$ ) therefore the very high concentrations of PAT-505 we determined to be present in mouse blood should have been sufficient to efficiently inhibit circulating ATX activity. Previous studies with PAT-505 administered at doses of $30 \mathrm{mg} / \mathrm{kg}$ once daily resulted in robust antifibrotic activity[39]. These studies evaluated plasma samples taken 24 hours after the last dose (trough) for ATX lysoPLD activity and trough concentrations in plasma and liver tissues, confirming good oral bioavailability and potency. The potency of PAT-505 against ATX lysoPLD activity was evaluated in vitro using recombinant mouse ATX and 16:0 LPC, 17:0 LPC, 18:0 LPC and 18:1 LPC as substrates. PAT-505 inhibited the ATX lysoPLD activity for all the LPC in a concentration dependent manner (Fig. 4D and 4E). Similar to published reports, PAT-505 potency was at nanomolar concentrations with the average $\mathrm{IC}_{50}$ values of $2.0-3.0 \mathrm{nM}$. Despite high dosing for a prolonged period, we observed very modest reduction in the levels of LPA in plasma. Even though the total level of LPA was reduced, only the levels of the species 18:2 LPA and 22:5 LPA were significantly reduced (Fig. 5). This is consistent with the findings of Katsifa et. al., who reported that out of the LPA species they measured following treatment of mice with PF8380, only LPA 18:2 was significantly reduced $[15,41]$. 
Cytokines and chemokines are increasingly implicated in cancer pathogenesis and present a target for innovative diagnostic and chemotherapeutic agents. Cancer cells can respond to circulating cytokines secreted by the host to promote growth, attenuate apoptosis and facilitate invasion and metastasis. Conversely certain cytokines that are released in response to infection, inflammation and immunity can inhibit cancer development and progress. Therefore, we examined the plasma concentration of a panel of cytokines in plasma from mice fed the casein or amino acid-defined high fat diets in combination with PAT-505 after tumor induction. Using the Magpix multiplex technology (Luminex Corp, Austin, TX) we determined that TGF- $\beta 1$ and TGF- $\beta 2$ levels were significantly reduced in mice that received amino acid-defined diets compared to casein diets (Figure 6). Treatment with PAT-505 reduced the levels of both TGF- $\beta 1$ and TGF- $\beta 2$ in casein mice to levels observed in AA-mice but did not have further reduction in AA-mice. In addition, feeding mice with amino acid-defined diets decreased the levels of pro-inflammatory cytokines IL-1 $\alpha$, IL-12 p40 and M-CSF, and chemokines MCP-1 (CCL2) and KC (CXCL1) compared with casein diets (Figure 6). Treatment with PAT-505 also decreased the levels of TGF- $\beta 1$, TGF- $\beta 2$, IL-1 $\alpha$, IL-12 p40, MCP-1 and KC compared with vehicle control (Figure 6). 


\section{Discussion}

We quantitated PC levels in various fat sources used to manufacturer rodent diets and the current findings demonstrate that casein is the major source of PC when present in rodent diets. We further show that replacing casein with amino acids based on casein profile in rodent high fat diets decreases the development of breast cancer in the estrogen-receptor positive syngeneic mouse model.

Although PC is the most abundant phospholipid in eukaryotic membranes and is critical for cell growth and organelle function there are no reports in the literature on the exact composition of PC in rodent diets. Most dietary formulations indicate the contents of choline but not phosphatidylcholine. Casein is usually added to diets as a standard source of protein with no consideration of the levels of PC it adds to diets. The quantities of casein included in diet formulas vary depending on the desired protein composition in these diets. For example, diets used to induce obesity such as western diets (45\% kcal from fat) contain approximately 195 $\mathrm{g} / \mathrm{kg}$, while high fat diets (60\% kcal from fat) are formulated with about $265 \mathrm{~g} / \mathrm{kg}$ diet weights. In some cases, casein is replaced with defined amino acids. These adjustments in casein quantities and composition would also alter PC composition of the rodent diets. The observation that casein is a significant source of PC may also be important to consider when explaining findings in the literature showing that choline-deficient diets containing higher levels of casein are resistant to induction of fatty liver in the nonalcoholic steatohepatitis (NASH) models[42-45]. This is because casein, loaded with PC, would effectively be a rich precursor that replenishes the omitted choline in the choline-deficient diets.

Our results reveal that formulating rodent diets with amino acids in place of casein reduce breast cancer development. The results are consistent with previous findings that suggest an association between higher dietary casein intake and increased risk of cancer[46-52]. Our study provides further evidence that the tumor promoting effects of casein is due to nutrients contained in casein since supplementing diets with all amino acids that are present in casein as replacement for casein decreases breast tumor development in mice. Casein is a significant source of calcium, phosphorus and vitamins. Therefore, we adjusted the levels of these nutrients by adding vitamin premix with choline and the two minerals to minimize variability among the diets we formulated. Dietary PC has been associated with increased cardiovascular disease risk[53]. We were interested in establishing whether casein also can promote tumor development by being a rich precursor source of PC metabolites. Orally administered PC is hydrolyzed in the intestinal lumen by phospholipase $\mathrm{A}_{2}$ to form LPC which is absorbed by enterocytes[54]. Some of the absorbed LPC is reacylated to form PC while the rest is hydrolyzed to LPA majorly by the enzyme ATX. Because of the potential of ATX to contribute to many diseases, a number of inhibitors have been described[24, 40, 55-58]. Many ATX inhibitors have been developed some with better in vivo bioavailability. We used the ATX inhibitor PAT-505 which has demonstrated 24-hour 
maximal inhibition of ATX activity with once daily dosing[39]. We reasoned that targeting LPA production by depleting PC in diet and inhibiting ATX activity with a potent drug would decrease tumor growth. We used LDLR knockout mice as they have higher circulating levels of LPA[27, 28]. PAT-505 treatment of mice only had modest effects as manifested by only the decreases of plasma concentrations of the saturated species of LPA (18:2-LPA and 22:5-LPA). The PAT-505 effects on other LPA species including unsaturated species was modest but statistically insignificant. However, in vitro PAT-505 inhibition assays showed nanomolar potency for both saturated and unsaturated LPC substrates. Our results reveal the existence of a discrepancy in potency of ATX inhibition in vitro and in vivo. Even though the ATX-dependent pathway is thought to be responsible for most of the LPA present in circulation, a possible explanation for the modest in vivo ATX inhibitory effect might be due to the mouse model we used. Given the large exess of substrate availability in hyperlipidemic mice fed high fat diet, it is very likely that the intended ATX inhibition was not achieved since the substrate was not a limiting factor for ATX-mediated LPA production. Furthermore, the presence of an ATX-independent pathway for LPA formation may lead to some resistance to ATX inhibition[59]. In this pathway, PC and other phospholipids are hydrolyzed by phospholipase $\mathrm{D}\left(\mathrm{PLD}_{1}\right.$ or $\left.\mathrm{PLD}_{2}\right)$ to generate phosphatidic acid (PA). LPA is then produced from PA by PLA 1 (acting typically on the sn-1 position of PA) or PLA 2 (acting on the sn-2 position). This hypothesis is also supported by the findings of Navab et al., who reported that the conversion of LysoPC 18:0 to LPA 18:0 was not altered by the ATX inhibitor PF8380 suggesting that the conversion is ATX independent in vivo[60]. In conditional ATX knockout mice, levels of ATX protein in all tissues tested were substantially reduced yet only LPA 18:2 levels were lowered to levels which were statistically significant[15]. Furthermore, in clinical trials that showed efficacy of the ATX inhibitor GLPG1690 in idiopathic pulmonary fibrosis, drug potency was evaluated by analyzing levels of only LPA 18:2 species[61]. Our observation of a lack of significant inhibition of primary tumor growth by PAT-505 may also be due to the fact that in the E0771 mouse tumor model we were unable to capture the delayed primary tumor growth observed with 4T1 mouse model. Benesch et al., showed in a study using the ATX inhibitor ONO-8430506 in the more aggressive 4T1 mouse breast cancer model that primary tumor growth was suppressed by the ATX inhibitor in the initial phase[26]. After 12 days of tumor growth, even with the continued treatment with ONO-8430506, the primary tumor growth caught up with the vehicle-treated growth with no significant differences thereafter. Furthermore, in our studies we also did not obtain conclusive data on metastasis to the lungs following treatment with PAT505 suggesting a lack of efficacy of ATX inhibition in the hyperlipidemic E0771 mouse model. However, ATX inhibition with ONO-8430506 in mice fed standard diet, decreases the number of 4T1 metastatic nodules to the lungs. Our results support the theory that factors other than ATX may be more important in driving the long term primary tumor growth when breast tumors invade the abdominal musculature. In addition, the threshold of ATX inhibition required to effect blockade of tumor growth in vivo is still unknown. 
Inflammation is a known risk factor associated with cancer initiation and progression[62-69]. Our results demonstrate that dietary casein contributes to increased levels of inflammatory mediators in plasma. Several cytokines and chemokines such as IL-1 $\alpha$, IL-1 $\beta$, TGF- $\beta 1$, TGF- $\beta 2$, IL-10, IL-12p40, LIX, IP-10, KC, MCP-1, MIP-1 $\beta$, M-CSF, MIG, RANTES and VEGF were significantly altered between casein and amino acid-defined diets suggesting that casein contributes to modifying levels of these factors in circulation. Some of these cytokines such as IL-1 and VEGF are known to promote angiogenesis, tumor growth and metastasis in experimental models. ATX/LPA nexus upregulates inflammatory signaling[70]. TGF- $\beta$ has dual role as a tumor suppressor and pro-oncogenic factor and is considered as a predictive biomarkers for progressive tumorigenesis[71]. In the early phase of epithelial tumorigenesis, it inhibits primary tumor development and growth. However, in the late stages of tumor progression, the role of TGF- $\beta$ becomes one of tumor promotion. Inhibition by PAT-505 also significantly reduced levels of the many of the cytokines and chemokines, although we did not observe a clear potentiation effects of combining ATX inhibition and replacing casein on the levels of circulating cytokines/chemokines.

\section{Conclusions}

Our study demonstrates for the first time that casein is the major source of PC when included as a protein ingredient in experimental diets. Levels of PC can be significantly reduced by either solvent stripping of fats from casein or replacing casein with amino acids. These findings provide the basis for adjusting levels of PC when formulating rodent diets especially in studies involving utilization of choline deficient diets. The rate of biosynthesis of PC by the endogenous Kennedy pathway is increased in mice receiving diets in which casein has been replaced by amino acids. We also showed that casein promotes primary tumor growth in the hyperlipidemic murine breast cancer models through a mechanism that involves pro-inflammatory signaling. The cancer-promoting effects of casein does not depend on production of LPA by ATX as inhibition of ATX did not attenuate primary tumor growth either singly or in combination with casein-replacement in these mice. However, the current study does have some limitations. For example, casein contains complex nutrient composition. Although the PC levels in casein is quite profound, it is also possible that the tumor enhancing effects of casein might be due to other factors/nutrients present in casein. A future study using amino acid defined control diets with added PC would be useful in validating the PC effects on tumor growth. Further studies to investigate the link between casein and breast cancer will be able to establish the metabolic processes associated with diets rich in casein and thus provide the basis for dietary approaches to mitigate cancer development and identifying biomarkers for therapeutic interventions. 


\section{Acknowledgements}

We thank Dr. Andrew J. Morris for providing mass spectrometry facilities, sharing expertise regarding LPA metabolism and critical review of the manuscript. We thank also Dr. Sony Soman and Courtney Hammill for support with mass spectrometry analysis. Dr. Colleen McMullen assisted in preparation and editing of this article.

\section{Funding}

This work was supported by grants from NCI K01 CA197073 (FOO); and NCI CRCHD P30CA177558 pilot grant to FOO. The content is solely the responsibility of the authors and does not necessarily represent the official views of the NIH.

\section{Availability of data and materials}

The datasets used and/or analyzed during this study are included in this published article or available from the corresponding author on reasonable request.

\section{Contributions}

FOO originated the study and was responsible for data collection, analysis, interpretation, and drafting the manuscript. FOO, EB, BY, and EA performed the experiments and participated in writing the manuscript. FOO and LC analyzed the data, edited the manuscript and discussed the data. All authors read and approved the manuscript.

\section{Corresponding author}

Correspondence to Fredrick O Onono foon222@uky.edu

\section{Ethical declarations}

\section{Ethical approval and consent to participate}

Not applicable

\section{Competing interests}

The authors declare that they have no competing interests 
Fig. 1. Levels of PC in Western and High Fat Diets formulated with casein or amino acids based on casein profile. The concentration of PC was normalized to the weights of diet pellets. Data shown are means $\pm \mathrm{SEM}$ of triplicate determinations. Statistical significance evaluated by Student's t-test $(* \mathrm{P}<0.001)$

\section{Fig. 2. Dietary deuterated choline contributes to plasma PC by the two distinct biosynthetic pathways. A.} Full scan spectrum indicating some of the most abundant lipids. Peaks for D9-PC(34:2) and D0-PC(34:2) are highlighted. B and C. product ion spectra showing the non-deuterated and D9-choline, respectively. D to I. Relative proportions of some of the most abundant PCs in mouse plasma from mice fed a diet containing deuterated choline. Comparison between groups was performed by Student $t$-test or repeated measures ANOVA [panels D-I], $* P \leq 0.05, * * p \leq 0.01, * * * P \leq 0.001, * * * * P \leq 0.0001$.

Fig. 3. Effects of manipulating dietary casein and ATX inhibition on the growth of breast cancers and lung metastasis. A. Primary tumor volumes of high fat diet-fed mice injected with E0771 tumor cells into the mammary fat pad and gavaged twice daily with either vehicle or PAT-505 $30 \mathrm{mg} / \mathrm{kg}$. Tumor volumes were calculated from caliper measurements using width ${ }^{2} \mathrm{X}$ length/2. Results are expressed as means $\pm \mathrm{SEM}$ for 7-8 mice/group. B. Masses of primary tumors resected on d 19 after implantation. Tumors resected from mice fed amino acid-defined diet and treated with PAT-505 were heavier than vehicle treated mice. $\mathrm{P}=0.016$. C. Tumor burden in the lungs measured by the number of visible lung metastatic nodules in mice one week after primary tumors were resected at $\mathrm{d} 19$, showing higher metastasis in mice fed casein-containing high fat diet. $\mathrm{P}<0.01$.

Fig. 4. PAT-505 plasma and tissue concentrations and in vitro ATX lysoPLD activity. PAT-505 in plasma and tissues was analyzed after continuous twice daily oral administration of PAT-505 to mice at a dosage of 30 $\mathrm{mg} / \mathrm{kg}$. A. Representative mass spectrometric chromatogram showing peaks for PAT-505 and PF8380 used for quantitation of PAT-505. B. Plasma PAT-505 concentration after one week of PAT-505 oral administration to mice ( $\mathrm{n}=7-9 /$ group). The drug concentration has been normalized using PAT-505 offline calibration and inclusion of PF8380 during sample extraction to monitor analyte recovery. C. PAT-505 concentration in tissues harvested after 21 days of treatment with PAT-505 or vehicle control. Values have been normalized to tissue weight. D and E. Effects of PAT-505 on in vitro lysoPLD activity was determined using recombinant mouse and human ATX, respectively, in the TOOS assay. Data represent the mean $\pm \mathrm{SEM}$ of triplicate determinations from at least three independent experiments.

Fig. 5. Effects of treating mice with $30 \mathrm{mg} / \mathrm{kg}$ PAT-505 on plasma molecular species of LPA. Mice were treated twice daily with $30 \mathrm{mg} / \mathrm{kg}$ PAT-505 and blood was collected after 7 days of continuous treatment. Control mice were gavaged with $0.5 \%$ Methylcellulose. Plasma LPA levels was determined by UPLC-MS/MS 
and concentrations expressed relative to C17:0-LPA internal standard. Results are means \pm SEM for 9-10 mice/group. ${ }^{*} \mathrm{P}<0.05$ vs. corresponding vehicle-treated mice.

\section{Fig. 6. Effects of manipulating casein in high fat diets and PAT-505 treatment on inflammatory} mediators in tumor bearing mice. Blood was collected from mice ( $\mathrm{n}=7-9 /$ group) 7 days after twice daily treatment with $30 \mathrm{mg} / \mathrm{kg}$ PAT-505. Circulating cytokines and chemokines were analyzed and compared between the two diet groups receiving vehicle or PAT-505 treatment. Values are expressed as means \pm SEM of duplicate determinations. Statistical significance was determined by Student's t-test. $* \mathrm{P}<0.05$ vs. corresponding vehicletreated mice.

\section{References}

1. Bray F, Ferlay J, Soerjomataram I, Siegel RL, Torre LA, Jemal A. Global cancer statistics 2018: GLOBOCAN estimates of incidence and mortality worldwide for 36 cancers in 185 countries. CA: a cancer journal for clinicians. 2018;68(6):394-424. Epub 2018/09/13. doi: 10.3322/caac.21492. PubMed PMID: 30207593.

2. Glunde K, Bhujwalla ZM, Ronen SM. Choline metabolism in malignant transformation. Nature reviews Cancer. 2011;11(12):835-48. Epub 2011/11/18. doi: 10.1038/nrc3162. PubMed PMID: 22089420; PubMed Central PMCID: PMCPMC4337883.

3. Gibellini F, Smith TK. The Kennedy pathway--De novo synthesis of phosphatidylethanolamine and phosphatidylcholine. IUBMB life. 2010;62(6):414-28. Epub 2010/05/27. doi: 10.1002/iub.337. PubMed PMID: 20503434. 4. Zeisel SH. A brief history of choline. Annals of nutrition \& metabolism. 2012;61(3):254-8. doi: 10.1159/000343120. PubMed PMID: 23183298.

5. Weihrauch JL, Son Y-SJJotAOCS. Phospholipid content of foods. 1983;60(12):1971-8. doi: 10.1007/bf02669968. 6. Zeisel SH, Da Costa KA, Franklin PD, Alexander EA, Lamont JT, Sheard NF, et al. Choline, an essential nutrient for humans. FASEB journal : official publication of the Federation of American Societies for Experimental Biology. 1991;5(7):2093-8. Epub 1991/04/01. PubMed PMID: 2010061.

7. Hofmann AF. Biliary secretion and excretion in health and disease: current concepts. Annals of hepatology. 2007;6(1):15-27. PubMed PMID: 17297425.

8. Zierenberg $\mathrm{O}$, Grundy SM. Intestinal absorption of polyenephosphatidylcholine in man. Journal of lipid research. 1982;23(8):1136-42. PubMed PMID: 7175371.

9. Labonte ED, Kirby RJ, Schildmeyer NM, Cannon AM, Huggins KW, Hui DY. Group 1B phospholipase A2-mediated lysophospholipid absorption directly contributes to postprandial hyperglycemia. Diabetes. 2006;55(4):935-41. PubMed PMID: 16567514; PubMed Central PMCID: PMC2048981.

10. Moolenaar WH, Hla T. SnapShot: Bioactive lysophospholipids. Cell. 2012;148(1-2):378-.e2. Epub 2012/01/24. doi: 10.1016/j.cell.2012.01.013. PubMed PMID: 22265422; PubMed Central PMCID: PMCPmc3645273.

11. Aoki J, Inoue A, Okudaira S. Two pathways for lysophosphatidic acid production. Biochimica et biophysica acta. 2008;1781(9):513-8. Epub 2008/07/16. doi: 10.1016/j.bbalip.2008.06.005. PubMed PMID: 18621144.

12. van Meeteren LA, Ruurs P, Stortelers C, Bouwman P, van Rooijen MA, Pradere JP, et al. Autotaxin, a secreted lysophospholipase $D$, is essential for blood vessel formation during development. Molecular and cellular biology. 2006;26(13):5015-22. Epub 2006/06/20. doi: 10.1128/mcb.02419-05. PubMed PMID: 16782887; PubMed Central PMCID: PMCPmc1489177.

13. Aoki J, Taira A, Takanezawa Y, Kishi Y, Hama K, Kishimoto T, et al. Serum lysophosphatidic acid is produced through diverse phospholipase pathways. The Journal of biological chemistry. 2002;277(50):48737-44. doi: 10.1074/jbc.M206812200. PubMed PMID: 12354767.

14. Moolenaar WH, Perrakis A. Insights into autotaxin: how to produce and present a lipid mediator. Nature reviews Molecular cell biology. 2011;12(10):674-9. doi: 10.1038/nrm3188. PubMed PMID: 21915140. 
15. Katsifa A, Kaffe E, Nikolaidou-Katsaridou N, Economides AN, Newbigging S, McKerlie C, et al. The Bulk of Autotaxin Activity Is Dispensable for Adult Mouse Life. PloS one. 2015;10(11):e0143083. Epub 2015/11/17. doi: 10.1371/journal.pone.0143083. PubMed PMID: 26569406; PubMed Central PMCID: PMCPMC4646642.

16. Brindley DN, Lin FT, Tigyi GJ. Role of the autotaxin-lysophosphatidate axis in cancer resistance to chemotherapy and radiotherapy. Biochimica et biophysica acta. 2013;1831(1):74-85. Epub 2012/09/08. doi:

10.1016/j.bbalip.2012.08.015. PubMed PMID: 22954454; PubMed Central PMCID: PMCPMC3584168.

17. David M, Wannecq E, Descotes F, Jansen S, Deux B, Ribeiro J, et al. Cancer cell expression of autotaxin controls bone metastasis formation in mouse through lysophosphatidic acid-dependent activation of osteoclasts. PloS one. 2010;5(3):e9741. Epub 2010/03/23. doi: 10.1371/journal.pone.0009741. PubMed PMID: 20305819; PubMed Central PMCID: PMCPmc2840030.

18. Gotoh M, Fujiwara Y, Yue J, Liu J, Lee S, Fells J, et al. Controlling cancer through the autotaxin-lysophosphatidic acid receptor axis. Biochemical Society transactions. 2012;40(1):31-6. Epub 2012/01/21. doi: 10.1042/bst20110608. PubMed PMID: 22260662; PubMed Central PMCID: PMCPmc3590848.

19. Liu S, Murph M, Panupinthu N, Mills GB. ATX-LPA receptor axis in inflammation and cancer. Cell cycle. 2009;8(22):3695-701. Epub 2009/10/27. PubMed PMID: 19855166; PubMed Central PMCID: PMCPmc4166520.

20. Liu S, Umezu-Goto M, Murph M, Lu Y, Liu W, Zhang F, et al. Expression of autotaxin and lysophosphatidic acid receptors increases mammary tumorigenesis, invasion, and metastases. Cancer cell. 2009;15(6):539-50. Epub 2009/05/30. doi: 10.1016/j.ccr.2009.03.027. PubMed PMID: 19477432; PubMed Central PMCID: PMCPmc4157573.

21. Meng G, Tang X, Yang Z, Benesch MGK, Marshall A, Murray D, et al. Implications for breast cancer treatment from increased autotaxin production in adipose tissue after radiotherapy. FASEB journal : official publication of the Federation of American Societies for Experimental Biology. 2017;31(9):4064-77. Epub 2017/05/26. doi:

10.1096/fj.201700159R. PubMed PMID: 28539367.

22. Popnikolov NK, Dalwadi BH, Thomas JD, Johannes GJ, Imagawa WT. Association of autotaxin and lysophosphatidic acid receptor 3 with aggressiveness of human breast carcinoma. Tumour biology : the journal of the International Society for Oncodevelopmental Biology and Medicine. 2012;33(6):2237-43. Epub 2012/08/28. doi: 10.1007/s13277-012-0485-1. PubMed PMID: 22922883.

23. Zhang H, Xu X, Gajewiak J, Tsukahara R, Fujiwara Y, Liu J, et al. Dual activity lysophosphatidic acid receptor panantagonist/autotaxin inhibitor reduces breast cancer cell migration in vitro and causes tumor regression in vivo. Cancer research. 2009;69(13):5441-9. Epub 2009/06/11. doi: 10.1158/0008-5472.can-09-0302. PubMed PMID: 19509223; PubMed Central PMCID: PMCPmc3446773.

24. Benesch MG, Ko YM, McMullen TP, Brindley DN. Autotaxin in the crosshairs: taking aim at cancer and other inflammatory conditions. FEBS letters. 2014;588(16):2712-27. Epub 2014/02/25. doi: 10.1016/j.febslet.2014.02.009. PubMed PMID: 24560789.

25. Benesch MG, Ko YM, Tang X, Dewald J, Lopez-Campistrous A, Zhao YY, et al. Autotaxin is an inflammatory mediator and therapeutic target in thyroid cancer. Endocrine-related cancer. 2015;22(4):593-607. Epub 2015/06/04. doi: 10.1530/erc-15-0045. PubMed PMID: 26037280.

26. Benesch MG, Tang X, Maeda T, Ohhata A, Zhao YY, Kok BP, et al. Inhibition of autotaxin delays breast tumor growth and lung metastasis in mice. FASEB journal : official publication of the Federation of American Societies for Experimental Biology. 2014;28(6):2655-66. Epub 2014/03/07. doi: 10.1096/fj.13-248641. PubMed PMID: 24599971. 27. Bot M, Bot I, Lopez-Vales R, van de Lest $\mathrm{CH}$, Saulnier-Blache JS, Helms JB, et al. Atherosclerotic lesion progression changes lysophosphatidic acid homeostasis to favor its accumulation. The American journal of pathology.

2010;176(6):3073-84. Epub 2010/05/01. doi: 10.2353/ajpath.2010.090009. PubMed PMID: 20431029; PubMed Central PMCID: PMCPMC2877866.

28. Navab M, Hough G, Buga GM, Su F, Wagner AC, Meriwether D, et al. Transgenic 6F tomatoes act on the small intestine to prevent systemic inflammation and dyslipidemia caused by Western diet and intestinally derived lysophosphatidic acid. Journal of lipid research. 2013;54(12):3403-18. Epub 2013/10/03. doi: 10.1194/jlr.M042051. PubMed PMID: 24085744; PubMed Central PMCID: PMCPMC3826687.

29. Upadhyay SK, Eckel-Mahan KL, Mirbolooki MR, Tjong I, Griffey SM, Schmunk G, et al. Selective Kv1.3 channel blocker as therapeutic for obesity and insulin resistance. Proceedings of the National Academy of Sciences of the United States of America. 2013;110(24):E2239-48. Epub 2013/06/05. doi: 10.1073/pnas.1221206110. PubMed PMID: 23729813; PubMed Central PMCID: PMCPMC3683782. 
30. Brainard RE, Watson $L$, Demartino AM, Brittian KR, Readnower RD, Boakye AA, et al. High fat feeding in mice is insufficient to induce cardiac dysfunction and does not exacerbate heart failure. PloS one. 2013;8(12):e83174. Epub 2013/12/25. doi: 10.1371/journal.pone.0083174. PubMed PMID: 24367585; PubMed Central PMCID: PMCPMC3867436. 31. Federico L, Ren H, Mueller PA, Wu T, Liu S, Popovic J, et al. Autotaxin and its product lysophosphatidic acid suppress brown adipose differentiation and promote diet-induced obesity in mice. Molecular endocrinology. 2012;26(5):786-97. doi: 10.1210/me.2011-1229. PubMed PMID: 22474126; PubMed Central PMCID: PMC3355557. 32. Fulkerson Z, Wu T, Sunkara M, Kooi CV, Morris AJ, Smyth SS. Binding of autotaxin to integrins localizes lysophosphatidic acid production to platelets and mammalian cells. The Journal of biological chemistry. 2011;286(40):34654-63. Epub 2011/08/13. doi: 10.1074/jbc.M111.276725. PubMed PMID: 21832043; PubMed Central PMCID: PMCPmc3186383.

33. Gellett AM, Kharel Y, Sunkara M, Morris AJ, Lynch KR. Biosynthesis of alkyl lysophosphatidic acid by diacylglycerol kinases. Biochemical and biophysical research communications. 2012;422(4):758-63. Epub 2012/05/26. doi: 10.1016/j.bbrc.2012.05.077. PubMed PMID: 22627129; PubMed Central PMCID: PMCPMC3377814.

34. Kim C, Schneider G, Abdel-Latif A, Mierzejewska K, Sunkara M, Borkowska S, et al. Ceramide-1-phosphate regulates migration of multipotent stromal cells and endothelial progenitor cells--implications for tissue regeneration. Stem cells (Dayton, Ohio). 2013;31(3):500-10. Epub 2012/11/30. doi: 10.1002/stem.1291. PubMed PMID: 23193025; PubMed Central PMCID: PMCPMC3582849.

35. Mendoza A, Breart B, Ramos-Perez WD, Pitt LA, Gobert M, Sunkara M, et al. The transporter Spns2 is required for secretion of lymph but not plasma sphingosine-1-phosphate. Cell reports. 2012;2(5):1104-10. Epub 2012/10/30. doi: 10.1016/j.celrep.2012.09.021. PubMed PMID: 23103166; PubMed Central PMCID: PMCPMC3616498.

36. Panchatcharam M, Salous AK, Brandon J, Miriyala S, Wheeler J, Patil P, et al. Mice with targeted inactivation of ppap2b in endothelial and hematopoietic cells display enhanced vascular inflammation and permeability.

Arteriosclerosis, thrombosis, and vascular biology. 2014;34(4):837-45. doi: 10.1161/ATVBAHA.113.302335. PubMed PMID: 24504738; PubMed Central PMCID: PMC4001868.

37. Selim S, Sunkara M, Salous AK, Leung SW, Berdyshev EV, Bailey A, et al. Plasma levels of sphingosine 1phosphate are strongly correlated with haematocrit, but variably restored by red blood cell transfusions. Clinical science. 2011;121(12):565-72. doi: 10.1042/CS20110236. PubMed PMID: 21749329; PubMed Central PMCID: PMC3174054.

38. Kraemer MP, Halder S, Smyth SS, Morris AJ. Measurement of Lysophosphatidic Acid and Sphingosine-1Phosphate by Liquid Chromatography-Coupled Electrospray lonization Tandem Mass Spectrometry. Methods in molecular biology. 2018;1697:31-42. Epub 2017/08/05. doi: 10.1007/7651_2017_55. PubMed PMID: 28770493; PubMed Central PMCID: PMCPMC6329001.

39. Bain G, Shannon KE, Huang F, Darlington J, Goulet L, Prodanovich P, et al. Selective Inhibition of Autotaxin Is Efficacious in Mouse Models of Liver Fibrosis. The Journal of pharmacology and experimental therapeutics. 2017;360(1):1-13. Epub 2016/10/19. doi: 10.1124/jpet.116.237156. PubMed PMID: 27754931.

40. Saga H, Ohhata A, Hayashi A, Katoh M, Maeda T, Mizuno H, et al. A novel highly potent autotaxin/ENPP2 inhibitor produces prolonged decreases in plasma lysophosphatidic acid formation in vivo and regulates urethral tension. PloS one. 2014;9(4):e93230. Epub 2014/04/22. doi: 10.1371/journal.pone.0093230. PubMed PMID: 24747415; PubMed Central PMCID: PMCPmc3991570.

41. Kaffe E, Katsifa A, Xylourgidis N, Ninou I, Zannikou M, Harokopos V, et al. Hepatocyte autotaxin expression promotes liver fibrosis and cancer. Hepatology (Baltimore, Md). 2017;65(4):1369-83. Epub 2016/12/17. doi: 10.1002/hep.28973. PubMed PMID: 27981605.

42. Aoyama Y, Yasui H, Ashida K. Effect of dietary protein and amino acids in a choline-deficient diet on lipid accumulation in rat liver. The Journal of nutrition. 1971;101(6):739-45. Epub 1971/06/01. doi: 10.1093/jn/101.6.739. PubMed PMID: 4102938.

43. Aoyama $\mathrm{Y}$, Matsumoto $\mathrm{H}$, Hitomi-Ohmura E, Yoshida A. Fatty liver induced by the addition of excess cystine to a soy-bean protein diet in rats. Comparative biochemistry and physiology Comparative physiology. 1992;102(1):185-9. Epub 1992/05/01. PubMed PMID: 1351814.

44. Liu YQ, Liu Y, Morita T, Mori M, Sugiyama K. Factors contributing to the resistivity of a higher casein diet against choline deficiency-induced hyperhomocysteinemia in rats. Journal of nutritional science and vitaminology.

2012;58(2):78-87. Epub 2012/07/14. PubMed PMID: 22790565. 
45. Santos JC, de Araujo OR, Valentim IB, de Andrade KQ, Moura FA, Smaniotto S, et al. Choline and Cystine Deficient Diets in Animal Models with Hepatocellular Injury: Evaluation of Oxidative Stress and Expression of RAGE, TNFalpha, and IL-1beta. Oxidative medicine and cellular longevity. 2015;2015:121925. Epub 2015/07/03. doi: 10.1155/2015/121925. PubMed PMID: 26137185; PubMed Central PMCID: PMCPMC4468296.

46. Cheng Z, Hu J, King J, Jay G, Campbell TC. Inhibition of hepatocellular carcinoma development in hepatitis B virus transfected mice by low dietary casein. Hepatology (Baltimore, Md). 1997;26(5):1351-4. Epub 1997/11/15. doi: 10.1002/hep.510260538. PubMed PMID: 9362383.

47. Hakkak R, Shaaf S, Jo CH, Macleod S, Korourian S. Effects of high-isoflavone soy diet vs. casein protein diet and obesity on DMBA-induced mammary tumor development. Oncology letters. 2011;2(1):29-36. doi: 10.3892/ol.2010.202. PubMed PMID: 22870124; PubMed Central PMCID: PMC3412466.

48. Shay $H$, Gruenstein M, Shimkin MB. EFFECT OF CASEIN, LACTALBUMIN, AND OVALBUMIN ON 3METHYLCHOLANTHRENE-INDUCED MAMMARY CARCINOMA IN RATS. Journal of the National Cancer Institute. 1964;33:243-53. Epub 1964/08/01. PubMed PMID: 14207844.

49. Tannenbaum A, Silverstone $H$. The genesis and growth of tumors; effects of varying the proportion of protein (casein) in the diet. Cancer research. 1949;9(3):162-73. Epub 1949/03/01. PubMed PMID: 18113452.

50. Toden S, Bird AR, Topping DL, Conlon MA. Resistant starch prevents colonic DNA damage induced by high dietary cooked red meat or casein in rats. Cancer biology \& therapy. 2006;5(3):267-72. Epub 2006/01/18. PubMed PMID: 16410726.

51. Vis EH, Geerse GJ, Klaassens ES, van Boekel MA, Alink GM. Possible mechanisms behind the differential effects of soy protein and casein feedings on colon cancer biomarkers in the rat. Nutrition and cancer. 2005;51(1):37-44. Epub 2005/03/08. doi: 10.1207/s15327914nc5101_6. PubMed PMID: 15749628.

52. Walters MA, Roe FJ. THE EFFECT OF DIETARY CASEIN ON THE INDUCTION OF LUNG TUMOURS BY THE INJECTION OF 9,10-DIMETHYL-1,2-BENZANTHRACENE (DMBA) INTO NEWBORN MICE. British journal of cancer. 1964;18:312-6. Epub 1964/06/01. PubMed PMID: 14189687; PubMed Central PMCID: PMCPMC2071307.

53. Zheng Y, Li Y, Rimm EB, Hu FB, Albert CM, Rexrode KM, et al. Dietary phosphatidylcholine and risk of all-cause and cardiovascular-specific mortality among US women and men. The American journal of clinical nutrition. 2016;104(1):173-80. Epub 2016/06/10. doi: 10.3945/ajcn.116.131771. PubMed PMID: 27281307; PubMed Central PMCID: PMCPMC4919531.

54. Tso $P$, Balint JA. Formation and transport of chylomicrons by enterocytes to the lymphatics. The American journal of physiology. 1986;250(6 Pt 1):G715-26. Epub 1986/06/01. doi: 10.1152/ajpgi.1986.250.6.G715. PubMed PMID: 3521320.

55. Albers HM, Dong A, van Meeteren LA, Egan DA, Sunkara M, van Tilburg EW, et al. Boronic acid-based inhibitor of autotaxin reveals rapid turnover of LPA in the circulation. Proceedings of the National Academy of Sciences of the United States of America. 2010;107(16):7257-62. doi: 10.1073/pnas.1001529107. PubMed PMID: 20360563; PubMed Central PMCID: PMC2867685.

56. Banerjee S, Norman DD, Lee SC, Parrill AL, Pham TC, Baker DL, et al. Highly Potent Non-Carboxylic Acid Autotaxin Inhibitors Reduce Melanoma Metastasis and Chemotherapeutic Resistance of Breast Cancer Stem Cells. Journal of medicinal chemistry. 2017;60(4):1309-24. Epub 2017/01/24. doi: 10.1021/acs.jmedchem.6b01270. PubMed PMID: 28112925.

57. Hausmann J, Kamtekar S, Christodoulou E, Day JE, Wu T, Fulkerson Z, et al. Structural basis of substrate discrimination and integrin binding by autotaxin. Nature structural \& molecular biology. 2011;18(2):198-204. Epub 2011/01/18. doi: 10.1038/nsmb.1980. PubMed PMID: 21240271; PubMed Central PMCID: PMCPmc3064516.

58. Stein AJ, Bain G, Prodanovich P, Santini AM, Darlington J, Stelzer NM, et al. Structural Basis for Inhibition of Human Autotaxin by Four Potent Compounds with Distinct Modes of Binding. Molecular pharmacology. 2015;88(6):98292. Epub 2015/09/16. doi: 10.1124/mol.115.100404. PubMed PMID: 26371182.

59. Black KE, Berdyshev E, Bain G, Castelino FV, Shea BS, Probst CK, et al. Autotaxin activity increases locally following lung injury, but is not required for pulmonary lysophosphatidic acid production or fibrosis. FASEB journal : official publication of the Federation of American Societies for Experimental Biology. 2016;30(6):2435-50. Epub 2016/03/24. doi: 10.1096/fj.201500197R. PubMed PMID: 27006447; PubMed Central PMCID: PMCPMC4871797. 
60. Navab M, Chattopadhyay A, Hough G, Meriwether D, Fogelman SI, Wagner AC, et al. Source and role of intestinally derived lysophosphatidic acid in dyslipidemia and atherosclerosis. Journal of lipid research. 2015;56(4):87187. Epub 2015/02/04. doi: 10.1194/jlr.M056614. PubMed PMID: 25646365; PubMed Central PMCID: PMCPmc4373744. 61. Maher TM, van der Aar EM, Van de Steen O, Allamassey L, Desrivot J, Dupont S, et al. Safety, tolerability, pharmacokinetics, and pharmacodynamics of GLPG1690, a novel autotaxin inhibitor, to treat idiopathic pulmonary fibrosis (FLORA): a phase 2a randomised placebo-controlled trial. The Lancet Respiratory medicine. 2018;6(8):627-35. Epub 2018/05/25. doi: 10.1016/s2213-2600(18)30181-4. PubMed PMID: 29792287.

62. Proceedings of the 4th International Conference on Eicosanoids and Other Bioactive Lipids in Cancer, Inflammation, and Radiation Injury. Hong Kong, October 4-7, 1995. Advances in experimental medicine and biology. 1997;407:1-599. PubMed PMID: 9417763.

63. Summaries for patients. Associations between cancer and inflammation of the muscles. Annals of internal medicine. 2001;134(12):S-12. PubMed PMID: 11419414.

64. Proceedings of the 16th IRIST Congress 2003: Peptide Radiopharmaceuticals in Diagnosis and Therapy of Cancer and Inflammation/Infection. May 8-10, 2003, Isle of Capri, Italy. Cancer biotherapy \& radiopharmaceuticals. 2004;19(2):173-270. PubMed PMID: 15584147.

65. From Chronic Inflammation to Cancer. Proceedings of the Falk Symposium 173, June 4-6, 2010, Brno, Czech Republic. Digestive diseases. 2010;28(4-5):573-692. PubMed PMID: 21394940.

66. Breast inflammation may drive cancer growth. The key is to shut down inflammation in the breast to stop breast cancer onset and progression. DukeMedicine healthnews. 2011;17(3):6. PubMed PMID: 21476242.

67. Abu-Amer Y. Inflammation, cancer, and bone loss. Current opinion in pharmacology. 2009;9(4):427-33. doi: 10.1016/j.coph.2009.06.007. PubMed PMID: 19577517; PubMed Central PMCID: PMC2731002.

68. Aggarwal BB, Gehlot P. Inflammation and cancer: how friendly is the relationship for cancer patients? Current opinion in pharmacology. 2009;9(4):351-69. doi: 10.1016/j.coph.2009.06.020. PubMed PMID: 19665429; PubMed Central PMCID: PMC2730981.

69. Aggarwal BB, Sung B. The relationship between inflammation and cancer is analogous to that between fuel and fire. Oncology. 2011;25(5):414-8. PubMed PMID: 21710836.

70. Wu Y, Zhu Z. Vascular endothelial growth factor receptor 1, a therapeutic target in cancer, inflammation and other disorders. Current medicinal chemistry. 2009;16(22):2890-8. PubMed PMID: 19689271.

71. Bierie B, Moses HL. Transforming growth factor beta (TGF-beta) and inflammation in cancer. Cytokine \& growth factor reviews. 2010;21(1):49-59. doi: 10.1016/j.cytogfr.2009.11.008. PubMed PMID: 20018551; PubMed Central PMCID: PMC2834863. 


\begin{tabular}{l|r}
\hline Component & $\begin{array}{r}\text { Concentration } \\
\text { (pmol/mg) }\end{array}$ \\
\hline Lard & 14.47 \\
TS - Lard & 0.50 \\
Beef tallow & 1.63 \\
Cocoa butter & 0.18 \\
Coconut oil & 2.15 \\
Palm oil & 0.12 \\
Corn oil & 1.19 \\
TS - corn oil & 0.35 \\
Casein & 605.65 \\
VFT Casein & 166.19 \\
\hline
\end{tabular}

Table 1. Concentration of PC in various fat sources used to manufacture rodent diets 737

\begin{tabular}{|l|r|r|r|r|}
\hline \multirow{2}{*}{$\begin{array}{l}\text { PC } \\
\text { Species }\end{array}$} & \multicolumn{4}{|c|}{ Concentration (pmol/mg) } \\
\cline { 2 - 5 } & Casein & $\begin{array}{l}\text { VFT } \\
\text { Casein }\end{array}$ & Lard & \multicolumn{1}{|l|}{$\begin{array}{l}\text { Anhydrous } \\
\text { Milk }\end{array}$} \\
\hline $34: 1 \mathrm{PC}$ & 157.97 & 62.98 & 4.09 & 2.83 \\
\hline $32: 0 \mathrm{PC}$ & 63.84 & 13.19 & 0.62 & 0.66 \\
\hline $32: 1 \mathrm{PC}$ & 38.70 & 8.91 & 0.35 & 0.34 \\
\hline $34: 0 \mathrm{PC}$ & 33.62 & 7.26 & 0.25 & 0.23 \\
\hline $34: 2 \mathrm{PC}$ & 20.58 & 3.54 & 0.78 & 0.33 \\
\hline $36: 1 \mathrm{PC}$ & 68.41 & 17.90 & 1.97 & 0.32 \\
\hline $36: 5 \mathrm{PC}$ & 46.38 & 11.05 & 0.07 & 0.16 \\
\hline $36: 2 \mathrm{PC}$ & 52.54 & 11.27 & 3.80 & 0.36 \\
\hline
\end{tabular}

Table 2. Comparison of the most abundant PC species in various dietary components 


\begin{tabular}{|c|c|c|c|}
\hline & $\begin{array}{c}\text { Casein WD } \\
\text { 21\% AMF Diet (0.2\% } \\
\text { Chol) (TD.09821) }\end{array}$ & $\begin{array}{l}\text { VFT-Casein WD } \\
\text { 21\% AMF Diet (VFT, } \\
0.2 \% \text { Chol, Green) } \\
\text { (TD.160726) }\end{array}$ & $\begin{array}{c}\text { AA }- \text { WD } \\
21 \% \text { AMF Diet } \\
\text { (AA, 0.2\% Chol, } \\
\text { Red) (TD.160725) }\end{array}$ \\
\hline Macronutrient Composition & (\% by weight) & (\% by weight) & (\% by weight) \\
\hline Protein & $17.3 \%$ & 17.3 & 17.2 \\
\hline Carbohydrate & $48.7 \%$ & 49.3 & 47.4 \\
\hline Fat & $21.2 .0 \%$ & 21.0 & 21.0 \\
\hline & (\% kcal from) & (\% kcal from) & (\% kcal from) \\
\hline Protein & 15.2 & 15.2 & 15.4 \\
\hline Carbohydrate & 42.9 & 43.3 & 42.4 \\
\hline Fat & 41.9 & 41.5 & 42.3 \\
\hline $\mathrm{Kcal} / \mathrm{g}$ & 4.5 & 4.6 & 4.5 \\
\hline Nutrients & g/Kg Diet & g/Kg Diet & g/Kg Diet \\
\hline Casein & 195 & & \\
\hline Casein, "Vitamin-Free" Test & & 188.56 & \\
\hline DL-Methionine & 3 & 3.0 & \\
\hline L-Alanine & & & 4.69 \\
\hline L-Arginine & & & 5.48 \\
\hline L-Asparagine & & & 5.29 \\
\hline L-Aspartic Acid & & & 10.61 \\
\hline L-Cystine & & & 0.55 \\
\hline L-Glutamic Acid & & & 33.85 \\
\hline Glycine & & & 2.82 \\
\hline $\begin{array}{l}\text { L-Histidine } \mathrm{HCl}, \\
\text { monohydrate }\end{array}$ & & & 5.91 \\
\hline L-Isoleucine & & & 8.02 \\
\hline L-Leucine & & & 14.12 \\
\hline L-Lysine $\mathrm{HCl}$ & & & 16.28 \\
\hline L-Methionine & & & 7.5 \\
\hline L-Phenylalanine & & & 7.97 \\
\hline L-Proline & & & 17.29 \\
\hline L-Serine & & & 8.78 \\
\hline L-Threonine & & & 6.43 \\
\hline L-Tryptophan & & & 1.84 \\
\hline L-Tyrosine & & & 8.74 \\
\hline L-Valine & & & 9.7 \\
\hline L-Glutamine & & & 28.68 \\
\hline Sucrose & 341.46 & 341.36 & 345.49 \\
\hline Corn Starch & 100.0 & 106.44 & 84.875 \\
\hline Maltodextrin & 50.0 & 50.0 & 50.0 \\
\hline Anhydrous Milkfat & 210.0 & 210.0 & 210.0 \\
\hline Cholesterol & 1.5 & 1.5 & 1.5 \\
\hline Cellulose & 50.0 & 50.0 & 50.0 \\
\hline $\begin{array}{l}\text { Mineral Mix, Ca-P Deficient } \\
\text { (79055) }\end{array}$ & & & 13.37 \\
\hline
\end{tabular}




\begin{tabular}{|l|c|c|c|}
$\begin{array}{l}\text { Mineral Mix, AIN-76 } \\
(170915)\end{array}$ & 35 & 35.0 & \\
\hline $\begin{array}{l}\text { Calcium Phosphate, } \\
\text { monobasic, monohydrate }\end{array}$ & & & 21.75 \\
\hline Calcium Carbonate & 4.0 & 4.0 & 8.325 \\
\hline $\begin{array}{l}\text { Vitamin Mix, Teklad } \\
(40060)\end{array}$ & 10.0 & 10.0 & 10.0 \\
\hline Ethoxyquin, antioxidant & 0.04 & 0.04 & 0.04 \\
\hline Green Food Color & & 0.1 & 0.1 \\
\hline Red Food Color & & & \\
\hline
\end{tabular}

741

742 Supplementary Table 1. Nutritional composition of the casein western diet (WD) (TD.09821), VFT-casein WD

743 (TD.160726) and Amino Acid (AA)-WD (TD.160725)

744 


\begin{tabular}{|c|c|c|}
\hline & $\begin{array}{l}\text { 60\% High Fat Diet } \\
\text { (TD.170339) }\end{array}$ & $\begin{array}{l}\text { 60\% High Fat Diet } \\
\text { (AA defined) } \\
\text { (TD.170341) }\end{array}$ \\
\hline Macronutrient Composition & (\% by weight) & (\% by weight) \\
\hline Protein & 23.5 & 23.1 \\
\hline Carbohydrate & 27.5 & 26.4 \\
\hline \multirow[t]{2}{*}{ Fat } & 34.3 & 34.0 \\
\hline & (\% kcal from) & (\% kcal from) \\
\hline Protein & 18.3 & 18.4 \\
\hline Carbohydrate & 21.5 & 21.0 \\
\hline Fat & 60.2 & 60.7 \\
\hline $\mathrm{Kcal} / \mathrm{g}$ & 5.1 & 5.0 \\
\hline Nutrients & $\mathrm{g} / \mathrm{Kg}$ Diet & g/Kg Diet \\
\hline Casein & 265.0 & \\
\hline L-Alanine & & 6.37 \\
\hline L-Arginine $\mathrm{HCl}$ & & 7.45 \\
\hline L-Asparagine & & 7.19 \\
\hline L-Aspartic Acid & & 14.42 \\
\hline L-Cystine & 4.0 & 4.15 \\
\hline L-Glutamic Acid & & 46.0 \\
\hline Glycine & & 3.83 \\
\hline L-Histidine $\mathrm{HCl}$, monohydrate & & 8.03 \\
\hline L-Isoleucine & & 10.9 \\
\hline L-Leucine & & 19.19 \\
\hline L-Lysine $\mathrm{HCl}$, & & 22.13 \\
\hline L-Methionine & & 6.11 \\
\hline L-Phenylalanine & & 10.83 \\
\hline L-Proline & & 23.5 \\
\hline L-Serine & & 11.93 \\
\hline L-Threonine & & 8.74 \\
\hline L-Tryptophan & & 2.5 \\
\hline L-Tyrosine & & 11.88 \\
\hline L-Valine & & 13.18 \\
\hline L-Glutamine & & 38.97 \\
\hline Sucrose & 90.0 & 100.6 \\
\hline Maltodextrin & 161.9 & 150.745 \\
\hline Lard & 310.0 & 310.0 \\
\hline Soybean Oil & 30.0 & 30.0 \\
\hline Cellulose & 65.5 & 65.5 \\
\hline $\begin{array}{l}\text { Mineral Mix, AIN-93G-MX } \\
(94046)\end{array}$ & 48.0 & \\
\hline Mineral Mix, w/o Ca \& P (98057) & & 18.36 \\
\hline Calcium Phosphate, dibasic & 3.4 & 20.92 \\
\hline Vitamin Mix, AIN-93-VX (94047) & 21.0 & 21.0 \\
\hline Choline Chloride & 1.1 & 1.1 \\
\hline Food Color & 0.1 & 0.1 \\
\hline
\end{tabular}


\begin{tabular}{|l|l|l|} 
Calcium Carbonate & 4.375 \\
\hline
\end{tabular}

745

746 Supplementary Table 2. Nutritional composition of the casein High Fat Diet (TD.170339) and Amino Acid

747 (AA) defined-High Fat Diet (TD.170341)

748

749

750 
Figure 1






\section{Figure 2}

A

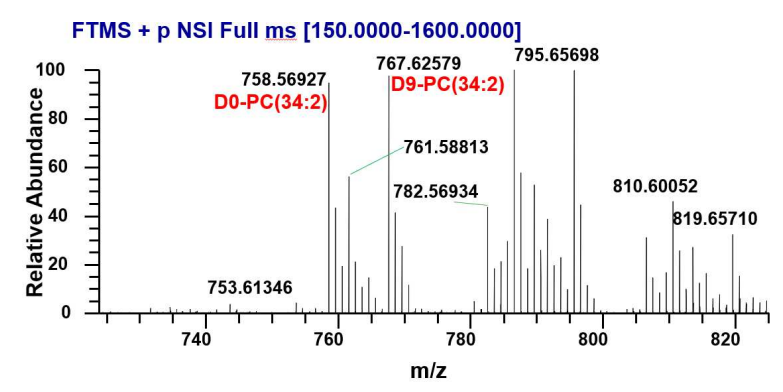

D

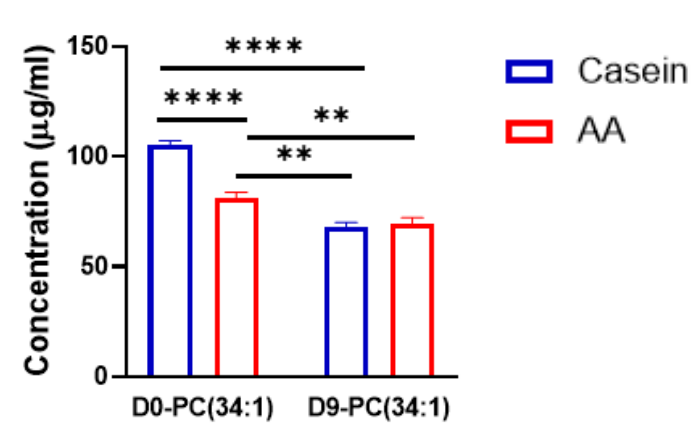

G

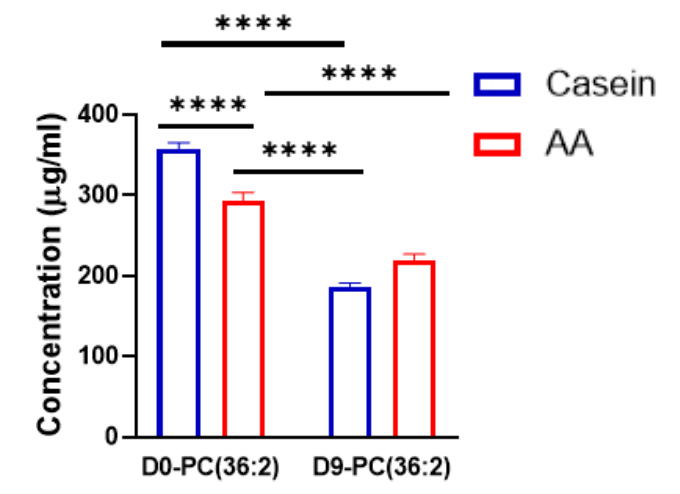

B

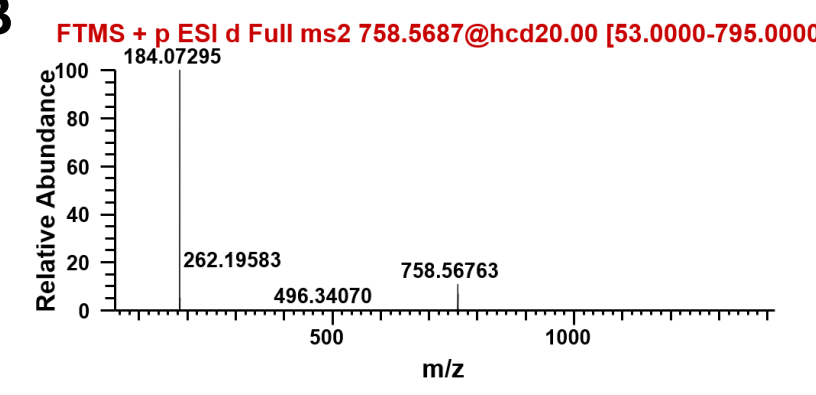

E

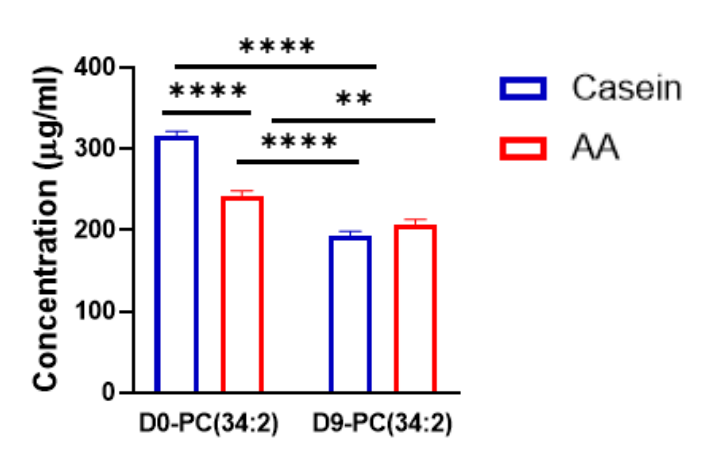

H

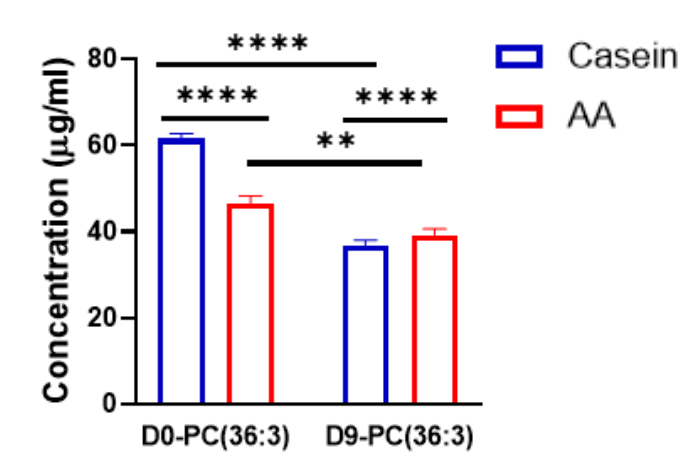

C

FTMS + p ESI d Full ms2 767.6243@hcd20.00 [53.6667-805.0000]

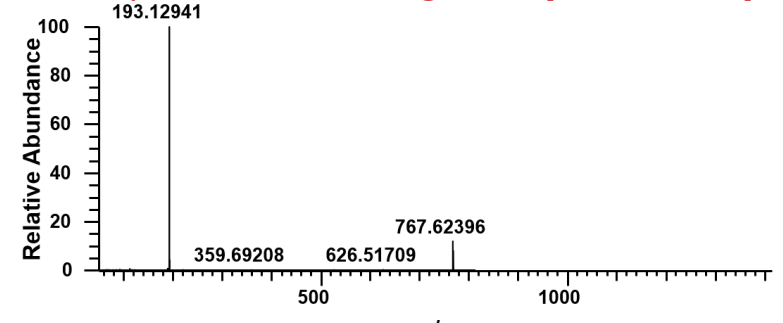

$\mathrm{m} / \mathbf{z}$
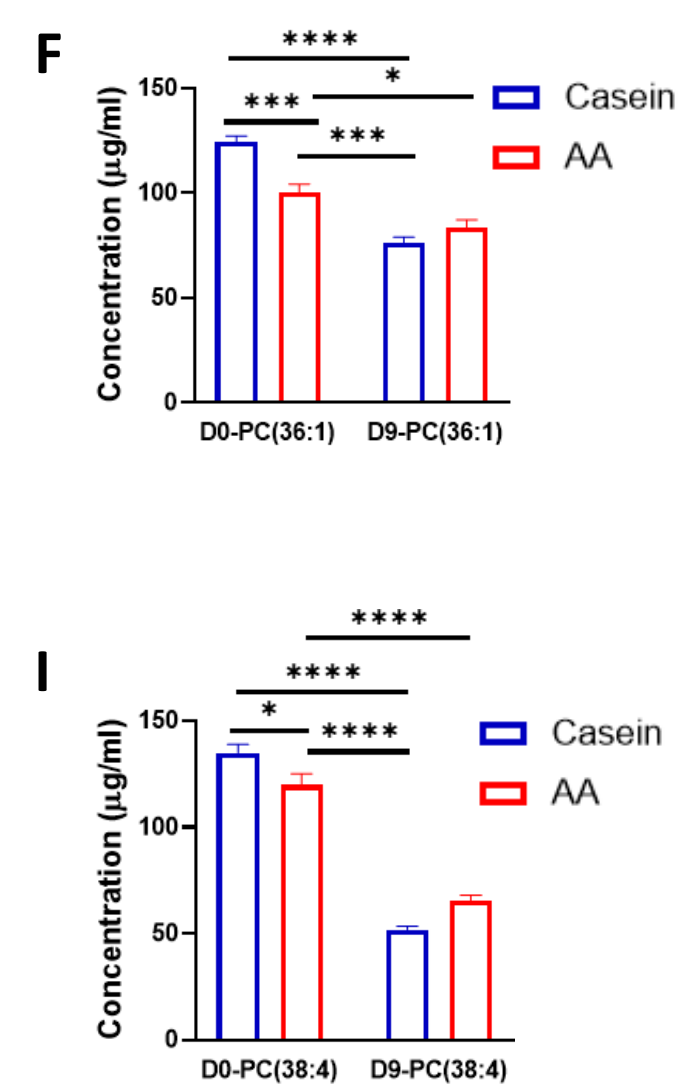
Figure 3

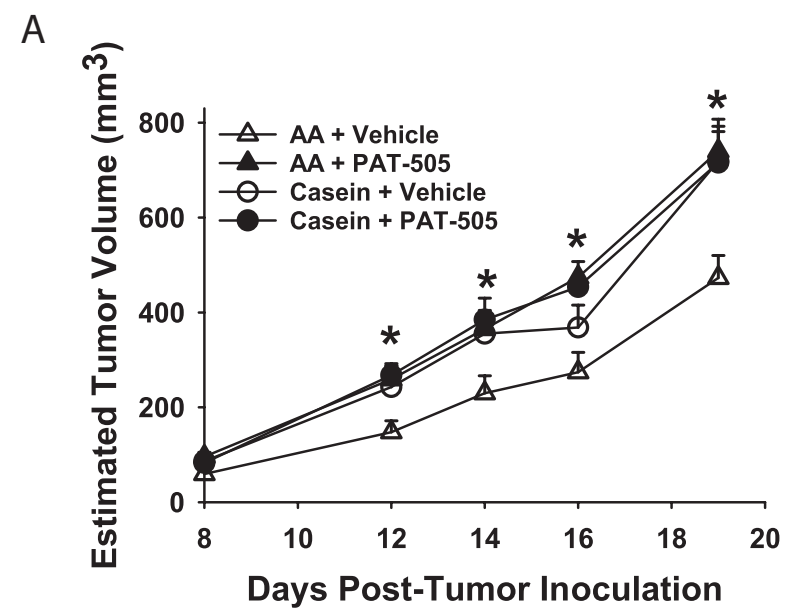

B

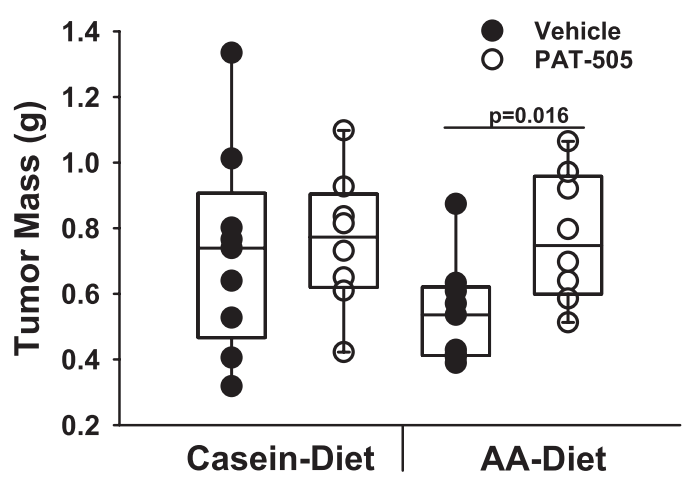

C

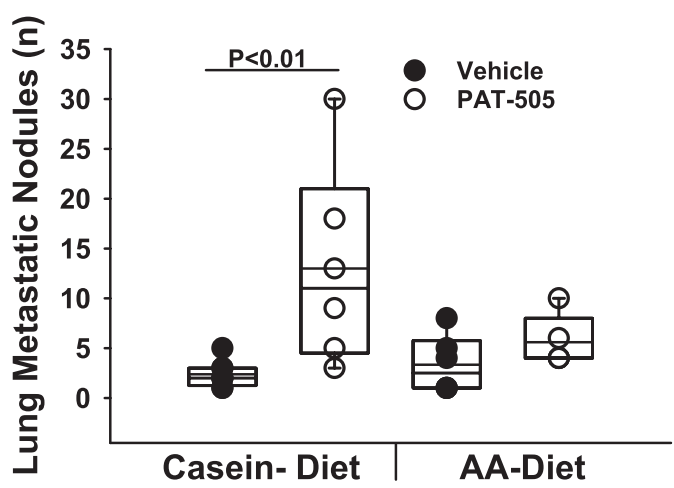


Figure 4

A

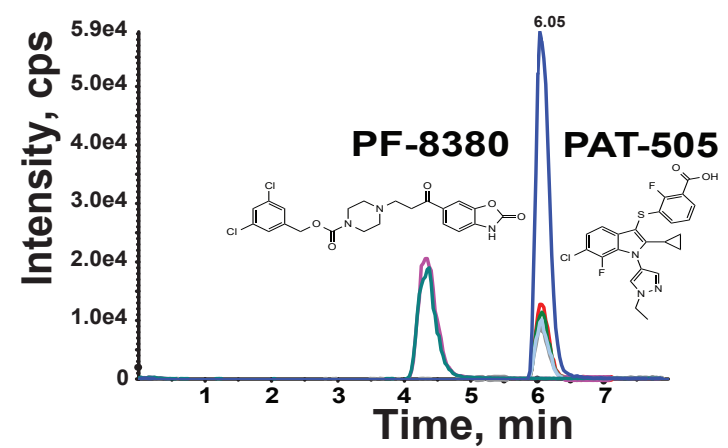

C

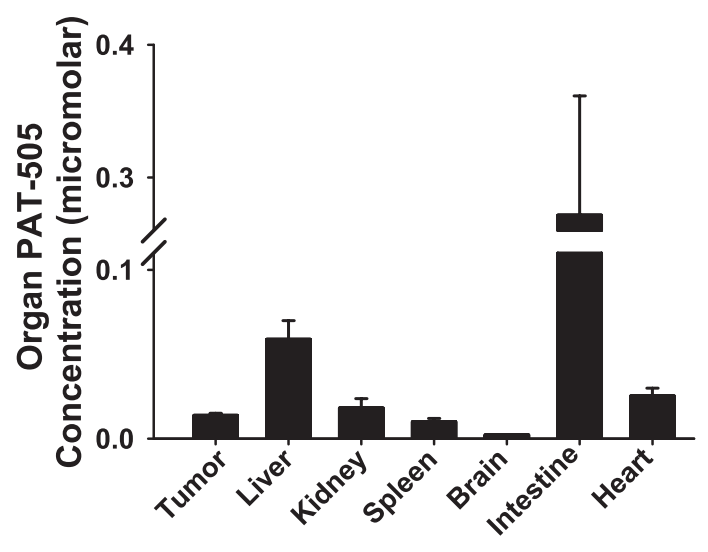

E

Human Recombinant ATX

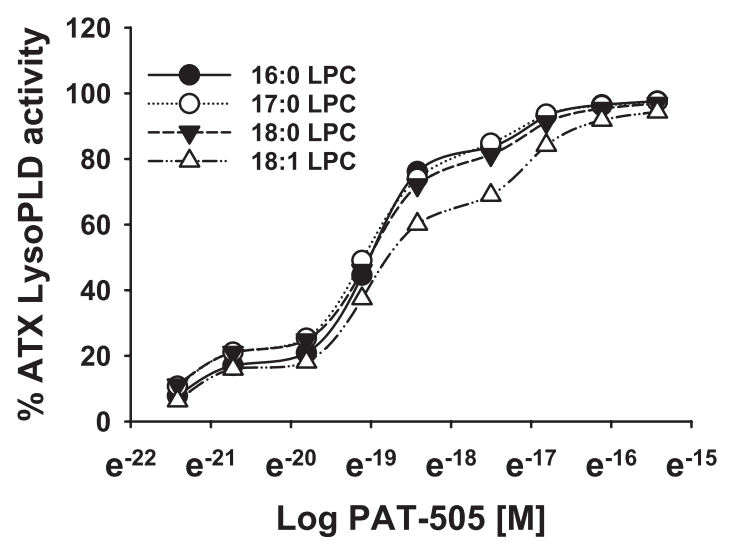

B

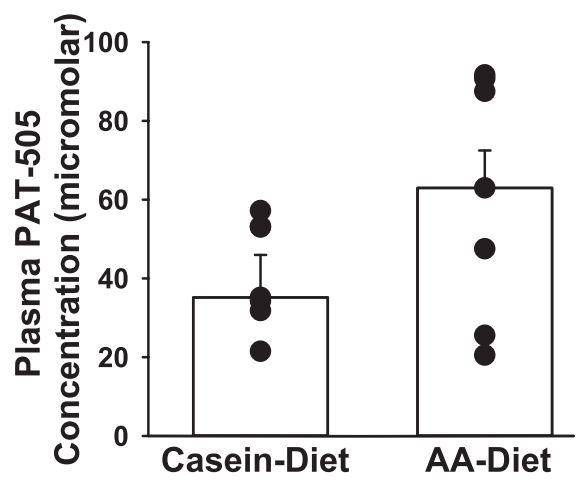

Mouse Recombinant ATX

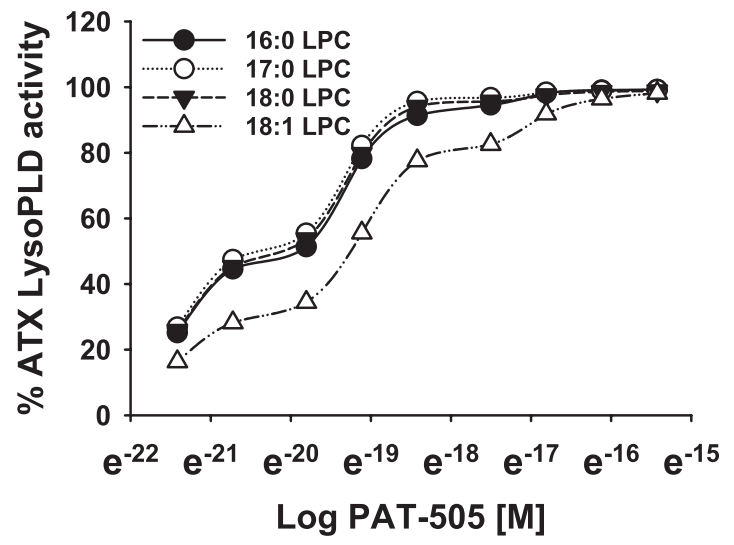


Figure 5
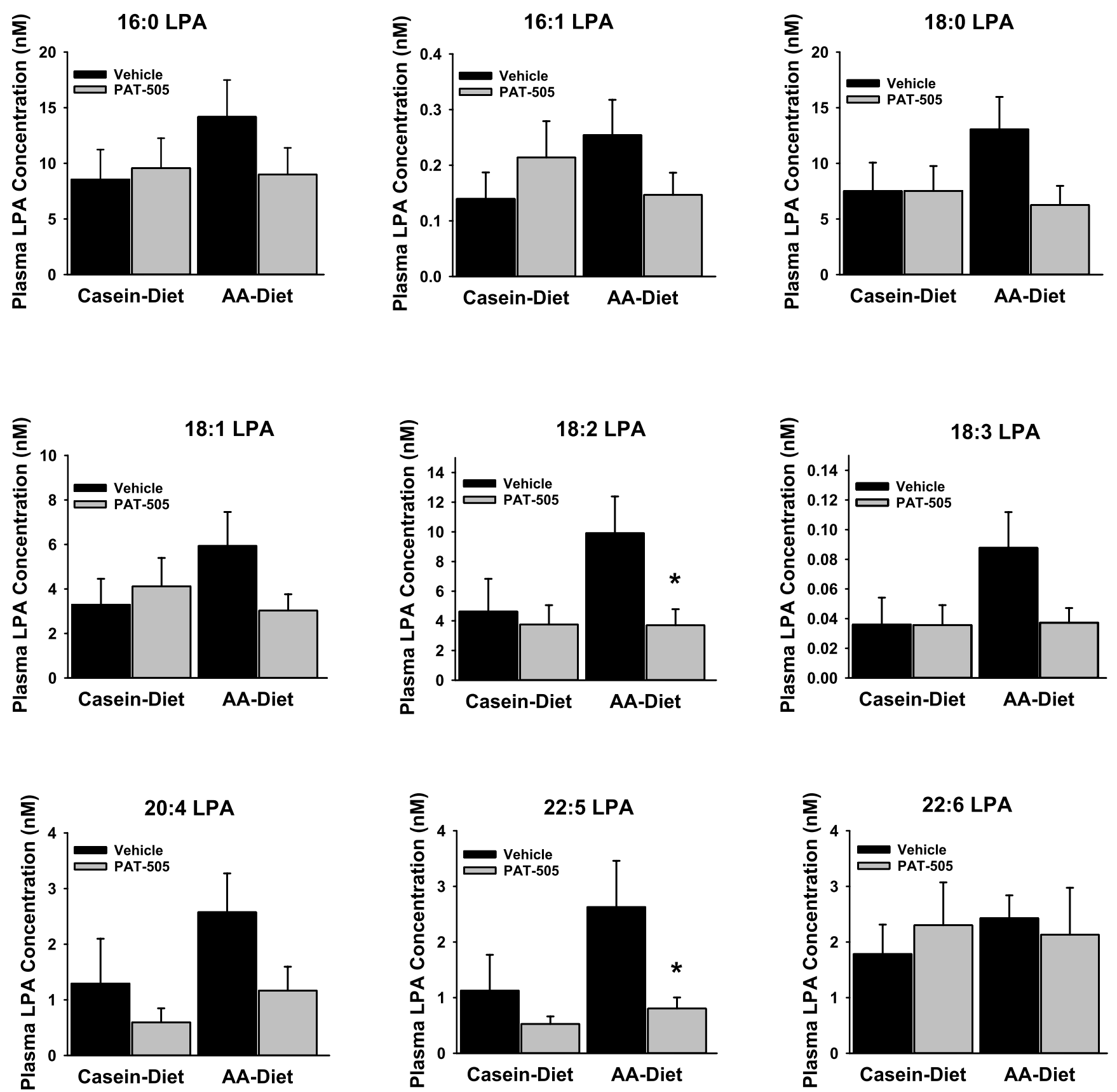
Figure 6
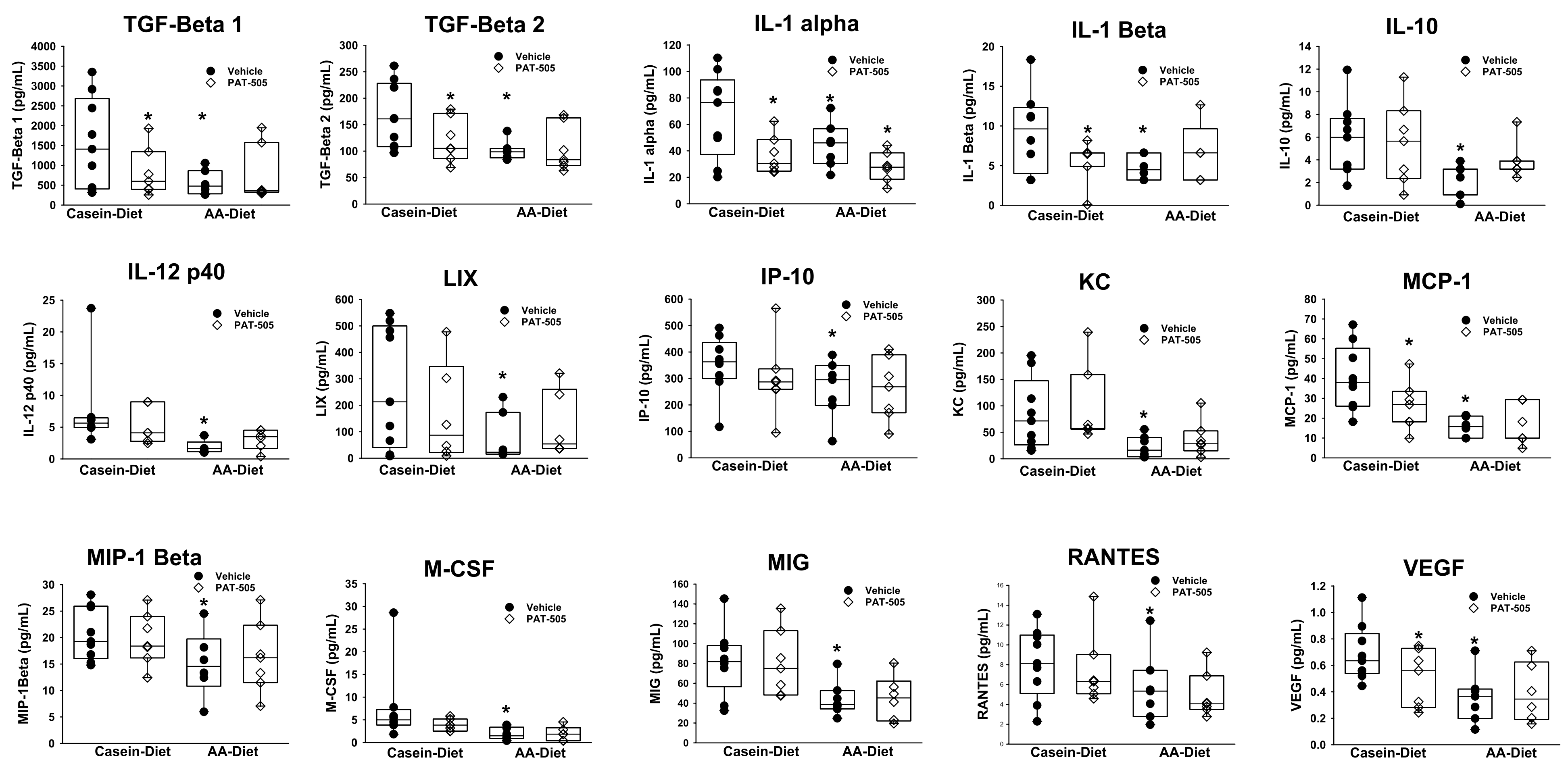
Figures

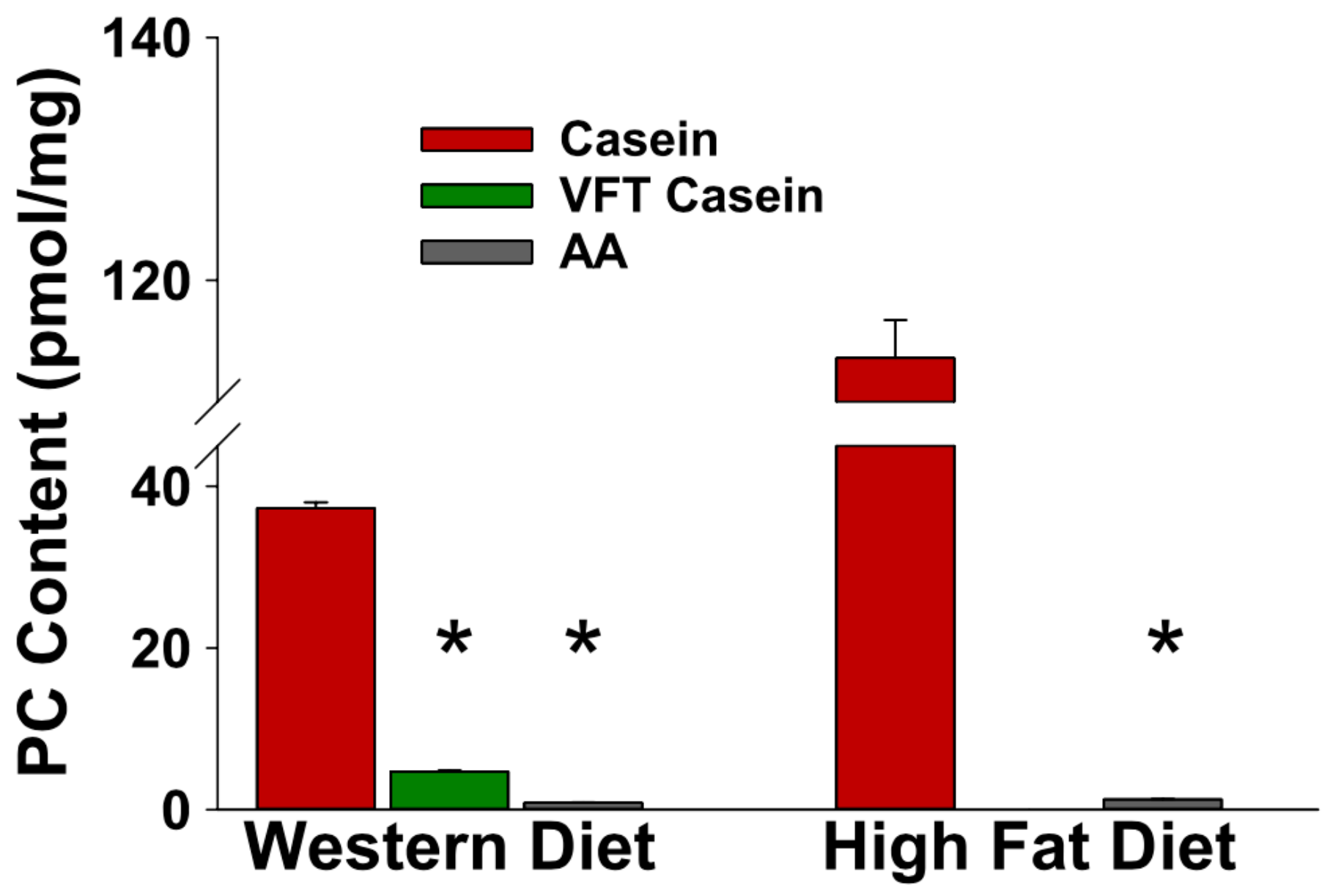

Figure 1

The results of our analysis show that both the western and high fat diets containing casein had the highest PC contents, while diets formulated with VFT Casein or amino acids had significantly reduced levels of PC 
A

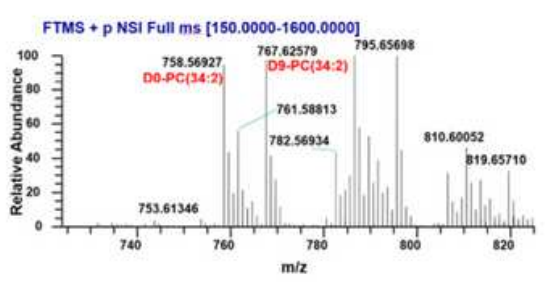

D

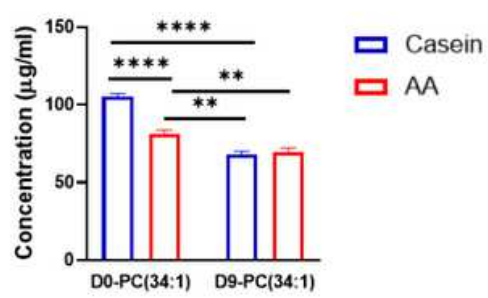

G

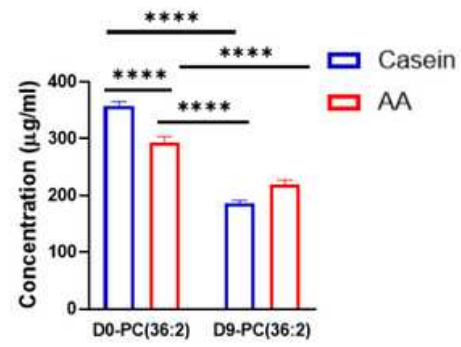

\section{B}

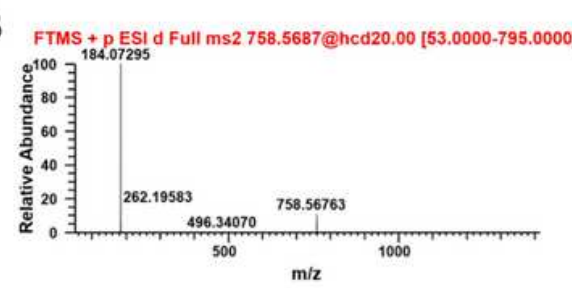

E

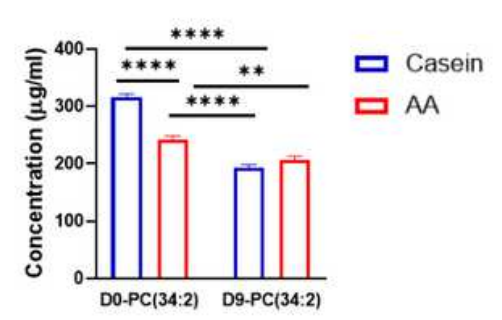

H

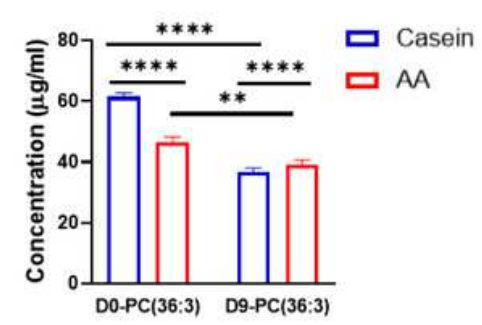

C
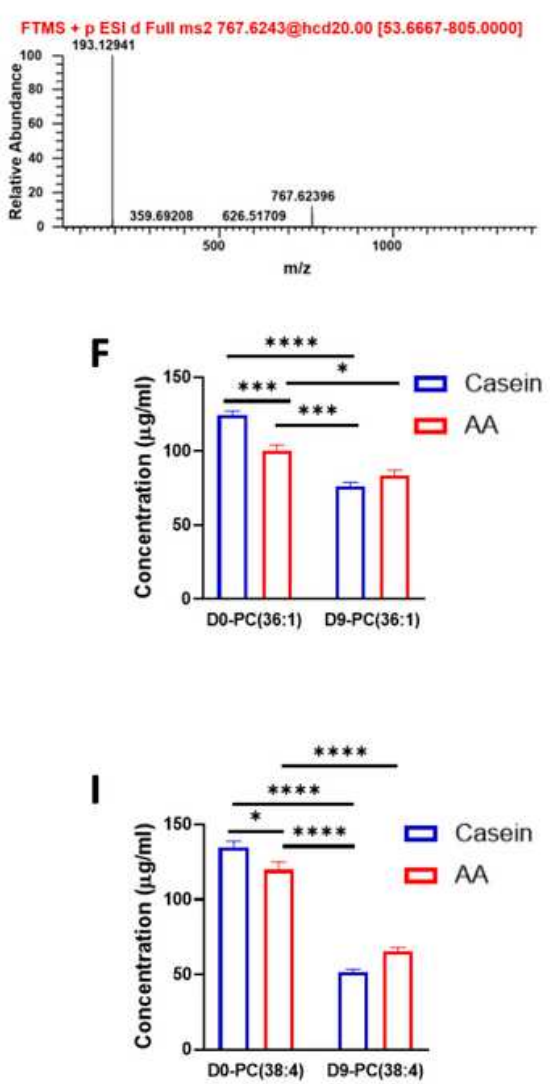

Figure 2

Fig. 2A depicts a representative section of the spectrum of the MS Scan and labeling of PC(34:2), one of the most abundant PC in the plasma of a mouse fed amino acid defined diet containing deuterium labeled choline. From their calculated exact masses, the highlighted peaks in the spectrum are the signals for D0-PC(34:2) at m/z 758.56927 formed from unlabeled choline, and D9-PC(34:2) at m/z 767.62579 which would have been generated from the deuterated choline supplied in the diets. We further analyzed these samples by LC/MS/MS using the Thermo Q-Exactive All-ions fragmentation (AIF) in positive mode to generate the product ions. As shown in Fig. 2 B and C, we observed a pattern corresponding to the D0and D9-choline present in the PC(34:2), represented by the m/z 184 and m/z 193 masses of the choline ion moieties respectively. TOF MS data were acquired in positive mode, ions corresponding to the e $\mathrm{m} / \mathrm{z}$ ratios of individual PCs extracted and analyzed using the AB Sciex OS Analytics program. A comparison of the ratios of deuterated PC to the unlabeled PC of the most abundant PCs showed that there was a higher degree of labeled PC in plasma from mice that were fed with the amino acid-defined diets Fig. 2D-I. 
A

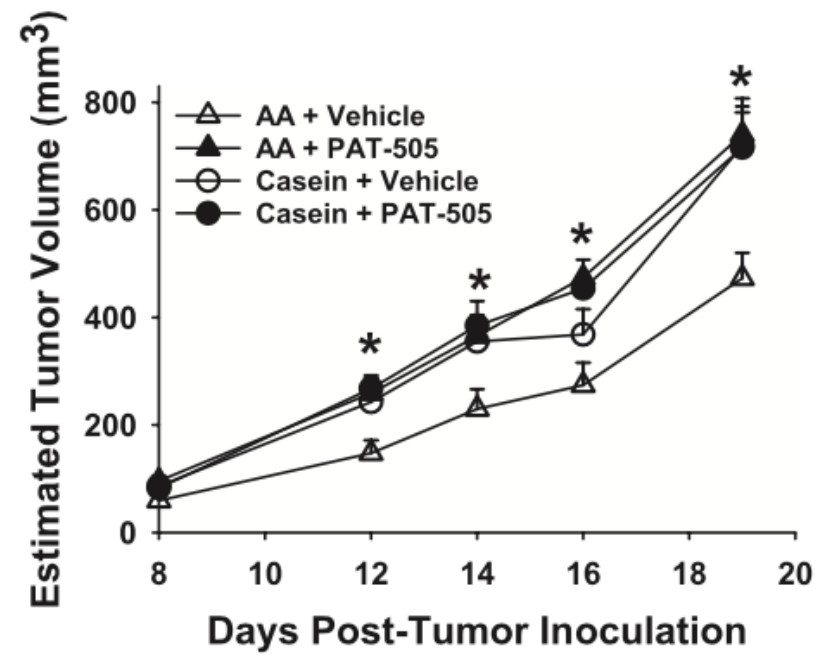

B

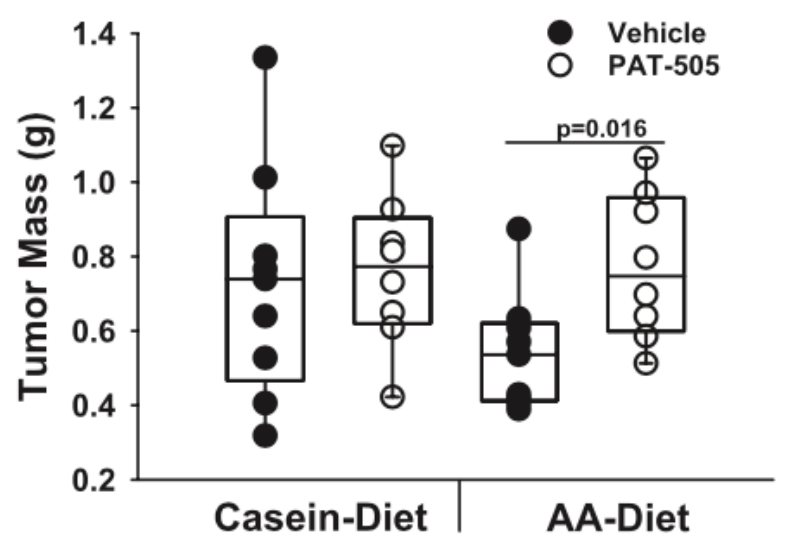

C

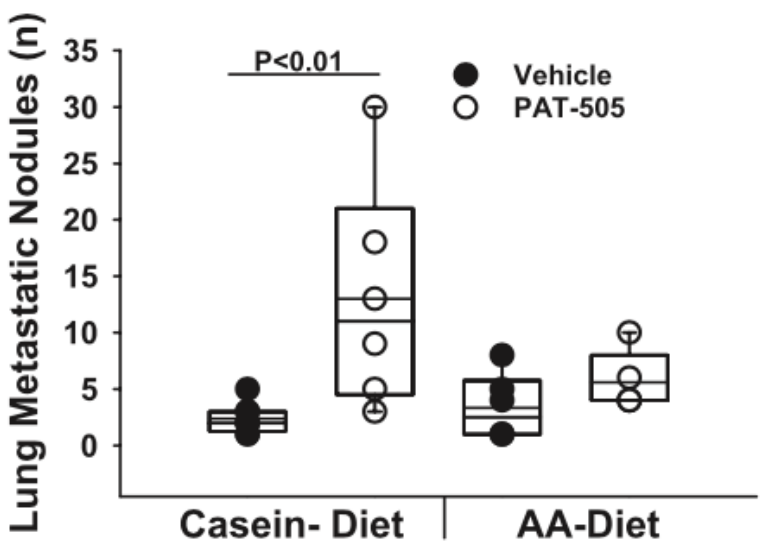

Figure 3 
A

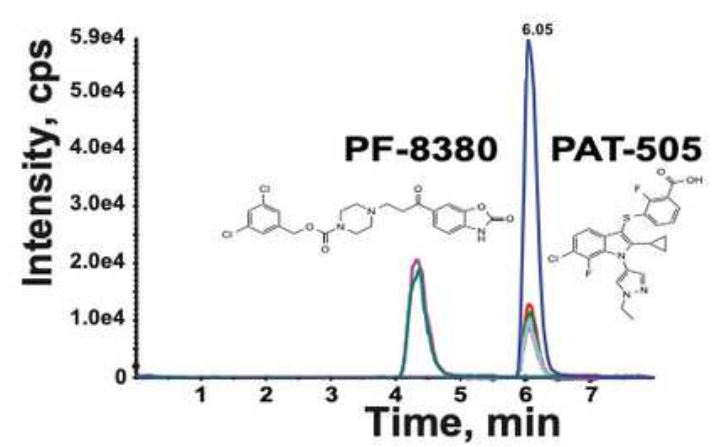

C

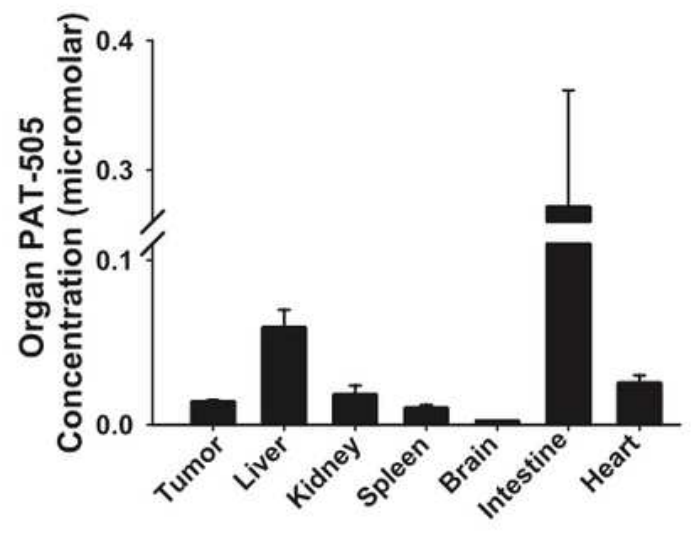

$E$
B

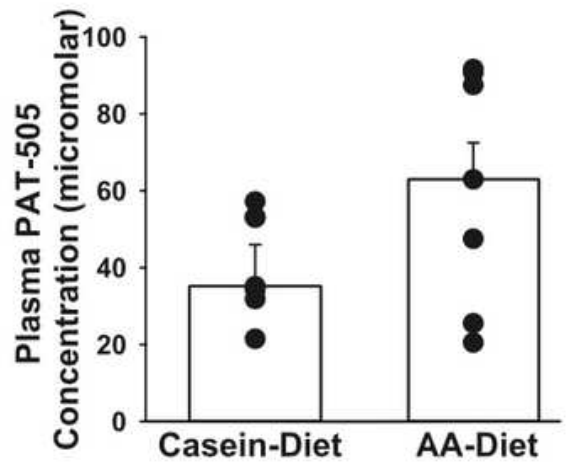

D Mouse Recombinant ATX

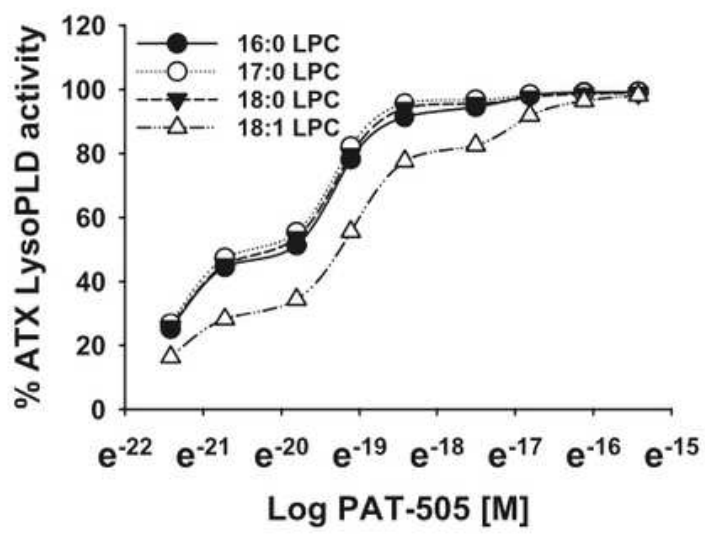

Human Recombinant ATX

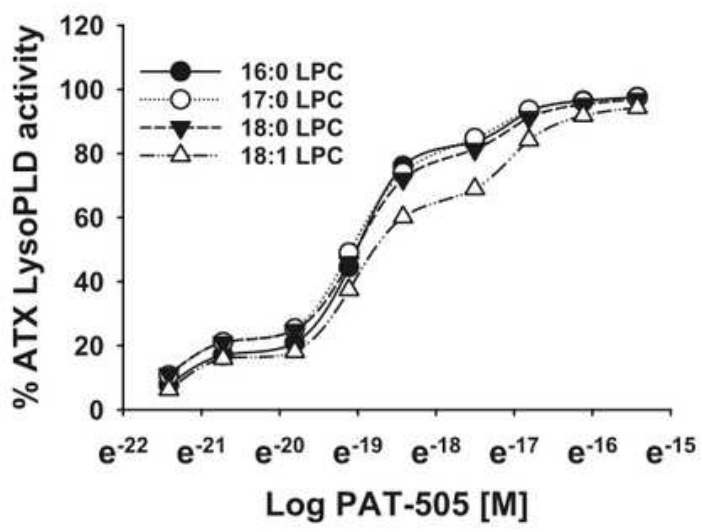

Figure 4

Using tandem MS methods we confirmed the bioavailability of PAT-505 in plasma and tissues harvested from our mice (Fig. 4A). We observed very high levels of circulating PAT-505 in plasma, reaching concentration levels of $60 \mu \mathrm{M}$ after one week of drug administration (Fig. 4B). These levels are consistent with the reported pharmacokinetic (PK) of PAT-505 as assessed in mice and rats[39]. We also determined PAT-505 levels in tissues that were harvested after the animals were sacrificed. PAT-505 was detected in 
the all the organs analyzed with the highest levels detected in the intestines and liver, while the lowest levels were present in the brain and spleen (Fig. 4C).
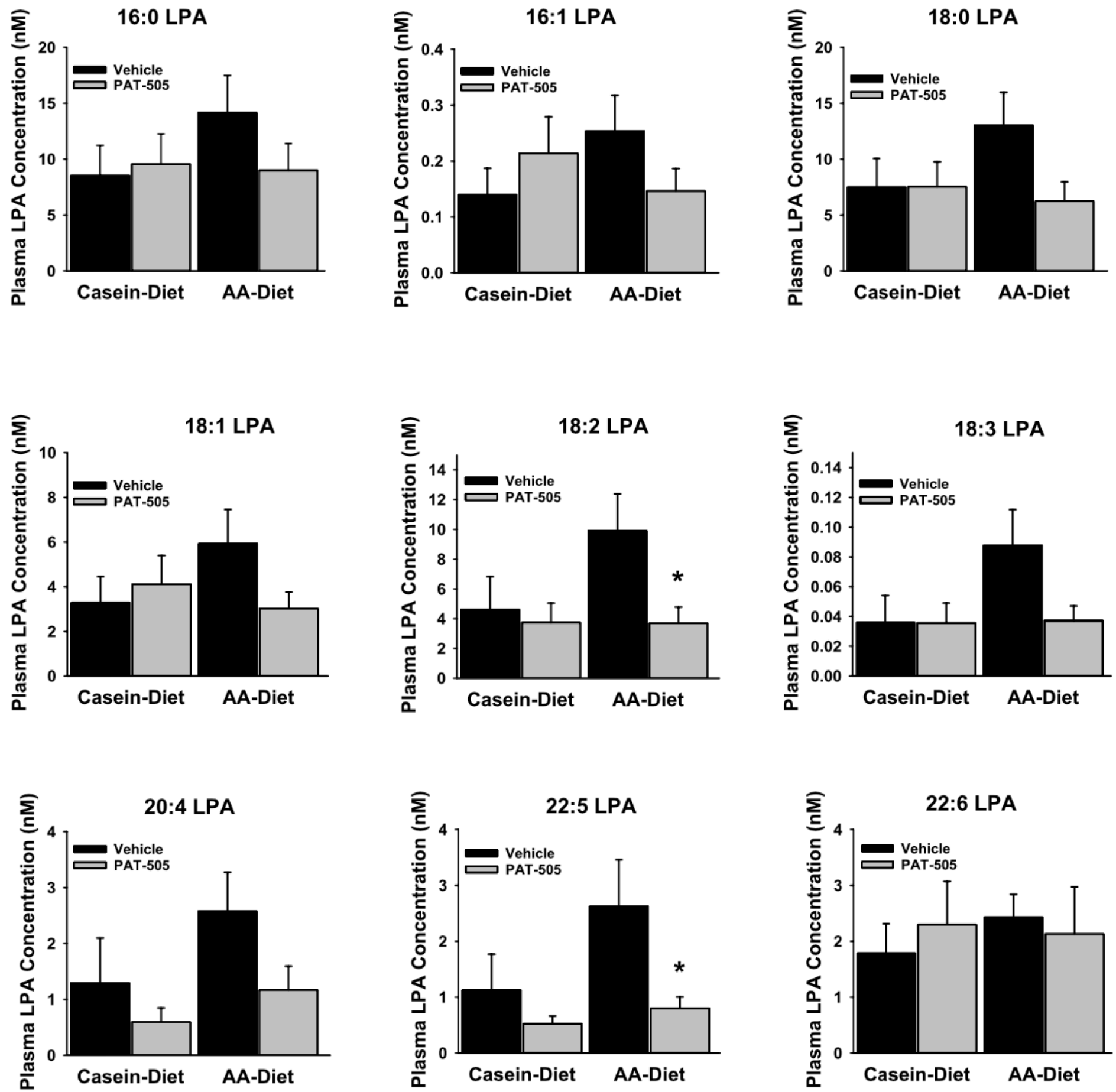

Figure 5

imilar to published reports, PAT-505 potency was at nanomolar concentrations with the average IC50 values of $352.0-3.0 \mathrm{nM}$. Despite high dosing for a prolonged period, we observed very modest reduction in the levels of LPA in plasma. Even though the total level of LPA was reduced, only the levels of the species 18:2 LPA and 22:5 LPA were significantly reduced (Fig. 5). 
TGF-Beta 1
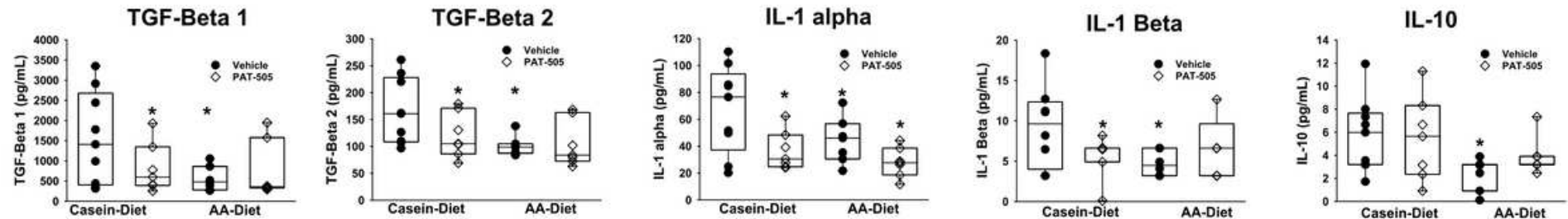

IL-12 p40
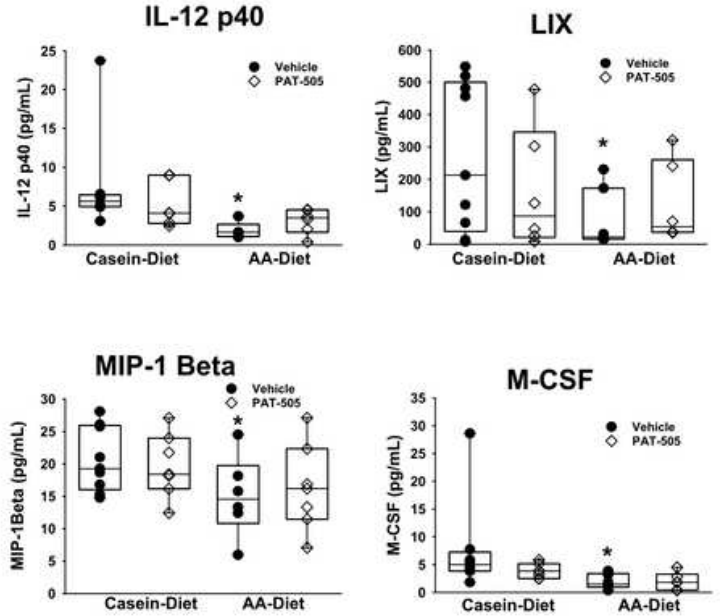
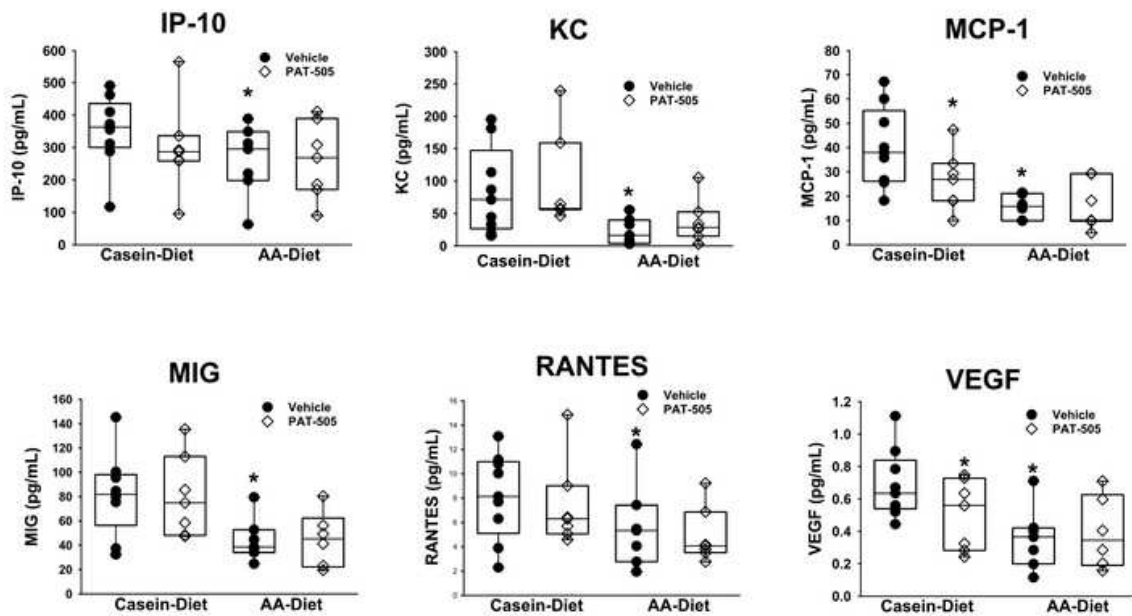

RANTES

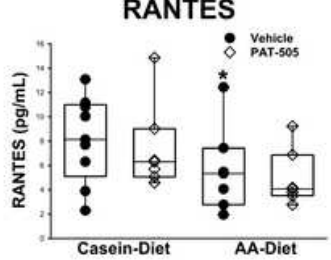

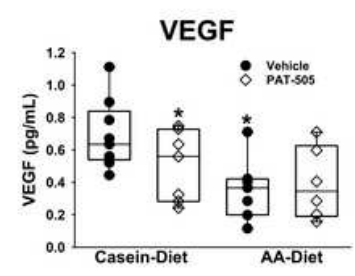

Figure 6

Using the 347 Magpix multiplex technology (Luminex Corp, Austin, TX) we determined that TGF- $\beta 1$ and TGF- $\beta 2$ levels 348 were significantly reduced in mice that received amino acid-defined diets compared to casein diets (Figure 6). 